\title{
In-Play Sports Betting: a Scoping Study
}

\author{
Elizabeth A. Killick ${ }^{1}$ - Mark D. Griffiths ${ }^{1}$
}

Published online: 16 April 2018

(C) The Author(s) 2018

\begin{abstract}
Technology has changed the nature of gambling practices over the last decade and is continuing to do so. The online sports betting industry has become a rapidly growing sector of the global economy, with online sports betting contributing $37 \%$ of the annual online gambling market in Europe. There has been an integration of social and technological processes that has enabled the cultural saliency of contemporary online betting. One of the more newly introduced forms of online sports betting is in-play sports betting behaviour (the betting on events within a sporting event such as football and cricket). In-play sports betting features (such as 'cash out') are increasing in popularity amongst online gambling operators. A scoping study was carried out examining the evolution of this new form of gambling practice which included both a systematic literature review and the examination of 338 online gambling websites that offered sports betting. The present study identified a comprehensive list of what in-play betting features are currently being offered on online gambling websites as well as other information concerning in-play sports betting. A total of 16 academic papers and two 'grey literature' reports and were identified in the systematic review. Out of 338 online gambling websites that were visited, $26 \%$ of these offered at least on in-play betting feature. Results from the systematic review suggest that in-play sports betting has the potential to be more harmful than other ways of gambling because of the inherent structural characteristics.
\end{abstract}

Keywords In-play betting $\cdot$ Sports betting $\cdot$ Live action betting $\cdot$ In-running betting $\cdot$ Cash out feature

The popularity of online gambling has markedly increased over the past decade, and it has been predicted that it will continue to grow in the coming years (Gray et al., 2012). Sports betting via the use of online platforms has already grown in popularity as a form of gambling

Elizabeth A. Killick

elizabeth.killick2017@my.ntu.ac.uk

Mark D. Griffiths

mark.griffiths@ntu.ac.uk

1 International Gaming Research Unit, Psychology Department, Nottingham Trent University, 50 Shakespeare Street, Nottingham NG1 4FQ, UK 
in numerous countries around the world (Lopez-Gonzalez and Griffiths 2016a), and betting with online sports bookmakers comprises $37 \%$ of the annual online gambling market in Europe (European Gaming \& Betting Association 2016). The value of remote betting (which includes betting online via PC, laptop, tablet, smartphone, television, etc.) has seen a substantial increase in recent years, with football betting and 'in-play' betting being a predominant driver of growth (Lopez-Gonzalez and Griffiths 2016a). In-play betting, also known as 'live action' betting or 'in-running' betting, refers to the wagering on an event that has started but not yet finished. Here, gamblers have the option to continue to bet once an event has started, and adapt their bets depending on how the event is progressing (e.g., on a sporting event such as a football or cricket match).

In-play betting first appeared towards the end of the 1990s when some bookmakers would take bets over the telephone whilst a sports event was in progress, and has now evolved into a popular online service in many countries (Odds Checker 2017). For example, in the UK, up to $25 \%$ of online gamblers have placed a bet in-play (Gambling Commission 2016). The online sports betting company Bet 365 reported that $80 \%$ of all their sports betting revenue is derived from in-play bets alone (Jackson 2015). The introduction of in-play betting has allowed bookmakers to increase the number of markets available to bet on during sports events, and gamblers are able to place bets based on many different types of in-game activity during the matches. For example, in football matches, it is possible to bet in on in-play markets including the match result, half-time score, number of goals scored in the first or second half of the game, the number of yellow cards during the match, and the name of the goal scorers. The availability of a particular sport and in-play markets varies from bookmaker to bookmaker.

Researchers have previously referred to the role of structural characteristics in the acquisition, maintenance, and development of online gambling behaviours (Parke and Griffiths 2007). Structural characteristics are those features that are inherent within the game itself and include features that are responsible for reinforcement and may in some cases facilitate excessive gambling (Griffiths et al. 2006). These characteristics include, but are not limited to, bet frequency (the number of bets placed within a given time frame), event frequency (the number of gambling events that are available to bet on in a given period), and pay-out frequency (the time between the end of the betting event and receiving the winning payment) (Griffiths and Auer 2013).

In-play sports betting has structural characteristics that have changed the mechanics of gambling for sports bettors, as they are now able to place a larger number of bets during a single sports game (as opposed to a single bet on who is going to win). It has been argued that structural characteristics of an event, including higher event frequency betting, are associated with problem gambling (Griffiths and Auer 2013; Harris and Griffiths 2017). One of the most important differences between being able to place an in-running sports bet opposed to a prematch bet is that the nature of the market has been turned what was previously a discontinuous form of gambling into a continuous one (Griffiths 2012; Griffiths and Auer 2013). The gambling study literature has suggested that in-play sports betting may offer more of a risk to problem gamblers because it allows the option for high-speed continuous betting and requires rapid and impulsive decisions in the absence of time for reflection (Hing et al. 2014a, b, c; Lopez-Gonzalez et al., 2017a, b, c, d; Nelson et al. 2008). Furthermore, marketing messages promoting online sports gambling have been become increasingly prevalent to media audiences (Lopez-Gonzalez and Griffiths 2016b).

Sports betting is one of the most commonly promoted forms of gambling in many countries, and access to this marketing activity has been associated with sports betting problems (Hing 
et al. 2016; Lopez-Gonzalez et al. 2017a). Advertisements often promote online sports betting as being easily accessible, anywhere at any time, using a mobile or other internet compatible device (Hing et al., 2017a, b; Lopez-Gonzalez et al. 2017a). There has also been a growth in inplay sports betting advertising. For example, within a sample of British and Spanish sports betting advertisements, in-play betting was prevalent in just under half of the adverts (LopezGonzalez et al., 2017a, b, c, d). One popular form of gambling advertising is the promotion of wagering inducements. These are often inducements that are promoted during a live event, and it has been suggested that doing so may promote impulse betting, where those placing a bet have an immediate chance to place the incentivised bet via a platform (Lamont et al. 2016). Inducements promoted during an in-match sporting event have been cited as a practice that may encourage in-play impulse betting intentions (Lamont et al. 2016).

Gambling companies have been known to promote mobile betting over other forms of gambling in their advertisements (Lopez-Gonzalez et al., 2017a, b, c, d) by overstating the illusion of control that gamblers perceive when placing bets via their smartphones (LopezGonzalez et al. 2017b). A main cognitive heuristic involved in the maintenance of gambling behaviour is the illusion of control (Langer 1975; Griffiths 1994). The illusion of control generates an expectency of success that is inappropriately higher than is objectively warranted (Langer 1975). In-play sports has the potential to enhance the illusion of control because gamblers are often able to dictate the speed of play, the volume of betting, and amount of money wagered, which may enhance both psychological perception and investments of control over their sports bet placement.

Whilst in-play sports betting features (such as the 'cash out' feature) are increasing in popularity amongst online gambling operators (Lopez-Gonzalez and Griffiths 2016b) and despite the growing body of research investigating the psychosocial and individual psychological factors determining gambling behaviour, much less attention has been devoted to understanding these factors in the context of in-play sports betting and the market characteristics of online sports betting. Therefore, the goal of the present scoping study was to identify what (i) has been published on the topic, (ii) empirical studies have been carried out, and (iii) in-play features are currently available to online sports gamblers via an examination of the world's leading sports betting sites.

\section{Method}

\section{Design and Materials}

A scoping study was carried out to investigate in-play sports betting. According to Mays, Roberts and Popay (2001), a scoping study aims to "map rapidly the key concepts underpinning a research area and the main sources and types of evidence available, and can be undertaken as stand-alone projects in their own right, especially where an area is complex or has not been reviewed comprehensively before" (p.194). A scoping review differs from traditional literature reviews in that it is a preliminary assessment of the potential size and scope of the available research literature and there is no attempt to control for the quality of the data or where it was obtained (Kavanagh et al. 2005). Scoping reviews also tend to address broader topics where many different study designs might be applicable, rather than focusing on a well-defined research question. They may also include information from non-academic sources (e.g., information available on websites). 
The current scoping study was carried out by (i) examining in-play sports betting literature (both academic and the non-academic 'grey' literature) and (ii) accessing and examining information obtained from online gambling websites that feature in-play betting facilities and features. As far as the authors are aware, the present paper is the first to examine availability of literature relating to online in-play sports betting and its specific features on online platforms. The scoping study focused on the following questions: (i) What in-play betting features have been made available to online sports betting users? (ii) What empirical research has been carried out on in-play sports betting? (iii) What has been theorised or speculated upon concerning in-play betting in the gambling studies literature?

\section{Procedure}

A comprehensive research strategy was adopted that involved searching for evidence from electronic databases: Scopus, Web of Science, PsycARTICLES, PsychINFO PubMED, ProQuest Dissertation and Thesis Global and Google Scholar. To identify any literature related to in-play betting, the follow search terms were used: "In-play [AND] betting", "Live [AND] action [AND] betting", "Online [AND] sports [AND] betting", "In-running [AND] betting", "In-play [AND] gambling", "Live [AND] action [AND] gambling", "Online [AND] sports [AND] gambling", "In-running [AND] gambling", "Internet [AND] sports [AND] gambling" and "internet [AND] sports [AND] betting". The studies were selected if they contained the following criteria: (i) being published in English and (ii) including any information (e.g., theoretical critique) or empirical data pertaining to in-play sports betting. Furthermore, reference lists of retrieved studies were also searched to identify any additional relevant studies. A flow diagram demonstrating this process is shown in Appendix Fig. 1.

Academic papers and grey literature were examined to identify any information relating to in-play sports betting. After 'scoping' the literature, a list of any academic papers (both empirical and theoretical) relating to in-play sports betting were identified and are described within the results section. Internet gambling websites were visited to see what features were currently available for in-play sports betting users. A list of 514 online bookmakers that offered online sports betting services was retrieved from the Top 100 Bookmakers (2017) website (http://www.top100bookmakers.com/completelist.php). The gambling websites visited were included for review if (i) they offered an online sports betting service, and (ii) it was possible to access the website in English. This resulted in a total of 338 online gambling websites from around the world being visited and reviewed. Those that offered in-play betting services were examined in further detail and are listed in Appendix Table $3(n=88)$. Different features from each of the websites were reviewed, including 'help and support areas', 'terms and conditions' and 'promotions'. These were examined to understand what in-play sports betting products, if any, were available for that website. After 'scoping' the websites, a list of in-play sports betting features were coded and are described in the results section and in Appendix Table 3.

\section{Results and Preliminary Discussion}

\section{In-Play Literature}

After conducting a systematic literature search, 2047 papers were identified. Once duplicate articles had been removed using Mendeley software and manual searching, 438 papers 
remained. Of these, 16 papers were identified which included empirical data or theorised about in-play sports betting in the gambling study literature. Thirteen of the papers were empirical, and three of the papers were theoretical and/or commentary based providing some kind of critique of in-play sports betting (see Table 1).

\section{Behavioural Tracking Data}

Prior to 2006, online gambling studies were predominantly based on self-reported methods and data (Griffiths et al. 2006). Since then, a number of studies have utilised behavioural tracking datasets provided by gaming operators (Griffiths 2014). Datasets provided by bwin have resulted in a series of empirical contributions regarding actual online gambling behaviour (Braverman and Shaffer 2010; Braverman et al. 2013; Gray et al., 2012; LaBrie et al. 2007; LaPlante et al. 2008; Nelson et al. 2008; Xuan and Shaffer 2009). Using a dataset of nearly 47,000 European gamblers, analyses have been conducted using two main approaches: (i) general behaviour descriptions of people who used one particular type of gambling product and (ii) behavioural data pertaining to account closures and the use of online responsible gambling features. In-play sports betting is one form of online gambling which has been examined in relation to its association with problem gambling. The remainder of this section looks at the main findings of these studies.

LaBrie et al. (2007) published the first research on actual gambling behaviour using the bwin data sample. This was a longitudinal study of sports gambling behaviour consisting of sample of 40,499 subscribers, studied over an 8-month period. The aim of the study was to describe Internet gambling behaviour, which was determined by analysing three variables converted to measure gambling involvement: number of daily bets, money bet, and money won. They found that within a sample of online sports bettors, in-play sports bettors (as opposed to those classified as fixed-odds gamblers who placed their bets prior to sports event starting) were more likely to be categorised as heavily involved gamblers (based on number of bets, amount wagers and net losses) when compared to fixed-odds gamblers. One limitation of this study is that this betting behaviour may not have been representative of the participant's total online gambling behaviour (e.g., bettors may play on other online sites or in betting shops). It was also noted that players other than the account holder may have bet using the online account (LaBrie et al. 2007). Finally, LaBrie et al. (2007) suggest that the progression of activities that lead to pathological gambling may require longer exposure to Internet gambling than the 8 months of gambling that were observed during their study.

LaPlante et al. (2008) reported that within a sample of 47,603 bwin subscribers, there was a decline in population participation, number of bets, and size of stakes during an 18 month period. However, this pattern was not seen amongst a sub-group of heavily involved bettors, particularly for in-play sports bettors. Those that placed bets in-play were found to maintain high levels of betting in the period following on from the initial subscription. Several limitations of the study were noted. For example, it was not possible to determine whether the sample utilised other online gambling activities as well as sports betting outside of the bwin website. It is possible that the decrease in gambling activity may have been because bettors moved their betting activity to a different gambling service provider. If this was the case, then it is noted that the overall gambling activity would have been underestimated. 
Table 1 Academic papers that discuss or empirically studied in-play sports betting (in alphabetical order of first author)

\begin{tabular}{lll}
\hline Study/paper $\quad$ Methodology & $\begin{array}{l}\text { Sample Results } \\
\text { size }\end{array}$ \\
\hline
\end{tabular}

\begin{tabular}{|c|c|}
\hline $\begin{array}{l}\text { Braverman and } \\
\text { Shaffer }(2010)\end{array}$ & $\begin{array}{l}\text { Behavioural } \\
\text { tracking }\end{array}$ \\
\hline $\begin{array}{l}\text { Braverman et al. } \\
\text { (2013) }\end{array}$ & $\begin{array}{l}\text { Behavioural } \\
\text { tracking }\end{array}$ \\
\hline
\end{tabular}

In-play bettors who were categorised by high-intensity, frequency and variability of amount staked during their first month of gambling were more likely to report gambling-related problems when closing their accounts.

Two groups of internet gamblers were found to have a higher risk of developing gambling-related problems. The first group engaged in three of more different gambling activities and showed high wager variability on casino games in their first month of using the gambling website. The second group participated in two different gambling activities and demonstrated high variability for in-play wagers.

Broda et al. (2008) Behavioural 160 tracking

Bettors who surpassed a self-imposed or default limit demonstrated a higher involvement in sports betting (i.e., bets per day and stake size). After receiving the notification, indicators of unfavourable gambling behaviours did not decline. There were no reported differences in the betting patterns of results for fixed-odds and in-play betting.

$\begin{array}{cc}\text { Brosowski et al. } & \begin{array}{c}\text { Behavioural } \\ \text { (2012) }\end{array} \\ \text { tracking }\end{array}$ Gambling involvement levels, including gambling on multiple game types, were predictive of gambling-related problems. Engaging in in-play betting or poker were significant predictors of at-risk gambling after controlling for multiple game involvement.

Gray et al. (2012) Behavioural 2066 tracking

Griffiths and Auer Theoretical $\begin{array}{r}\text { Not } \\ \text { appli- } \\ \text { cable }\end{array}$

Hing et al. (2016) Self-report

Hing et al. 2017a) Self-report

LaBrie et al. (2007) Behavioural tracking

LaPlante et al. (2008)
Behavioural tracking 1816 40,499

Online gamblers who triggered a responsible gambling alert were distinguished from control cases using indices of the intensity of gambling activity (e.g., number of bets per betting day, total number of bets made). Those who triggered the responsible gambling alert were likely to engage in in-play sports betting than those who did not.

The paper argued that structural characteristics, including event frequency, appear to be a contributing factor in problem gambling. It was argued that in-play betting had changed the structural characteristics of sports betting from one that was typically discontinuous (e.g., a weekly bet on the outcome of a football game) to a 'continuous' form of gambling with an increased event frequency that is associated with problem gambling.

The risk of experiencing gambling-related problems was associated with a higher number of bets being placed in-play, before an event has started; and on impulse before or during a match.

Impulsive sports bettors (characterised as having higher trait impulsiveness, more frequent sports betting behaviour, higher problem gambling severity and a shorter history of sports betting) were more likely to bet on in-play sporting events than overall match outcomes.

In-play bettors placed on average 2.8 wagers of $€ 4$ every fourth day compared with fixed-odds bettors who placed 2.5 bets of $€ 4$ every fourth day. Mean net losses were smaller for in-play bets. Those who bet in-play on sports (as opposed to those who bet before matches) were categorised more often as heavily involved gamblers.

47,603 Most of the sample demonstrated a rapid decrease in the number of bets made and the stake size wagered. Betting frequency was higher for fixed-odds events. However, after 
Table 1 (continued)

\begin{tabular}{|c|c|c|c|}
\hline Study/paper & Methodology & $\begin{array}{l}\text { Sample } \\
\text { size }\end{array}$ & Results \\
\hline & & & $\begin{array}{l}3 \text { months, the amount wagered on in-play events surpassed } \\
\text { wagers placed on fixed-odds events. }\end{array}$ \\
\hline $\begin{array}{l}\text { LaPlante et al. } \\
\text { (2014) }\end{array}$ & Self-report & 1440 & $\begin{array}{l}\text { In-play sports betting demonstrated a significant relationship } \\
\text { with potential gambling-related problems, after controlling } \\
\text { for depth and breadth of gambling involvement. }\end{array}$ \\
\hline $\begin{array}{l}\text { Lopez-Gonzalez and } \\
\text { Griffiths (2017) }\end{array}$ & Theoretical & $\begin{array}{l}\text { Not } \\
\text { appli- } \\
\text { cable }\end{array}$ & $\begin{array}{l}\text { It was theorised that the in-play 'cash-out' feature has struc- } \\
\text { tural characteristics that allows bettors to feel more in } \\
\text { control of their bets and may make gamblers lose control of } \\
\text { their bets. }\end{array}$ \\
\hline $\begin{array}{l}\text { Lopez-Gonzalez } \\
\text { et al., } 2018\end{array}$ & Self-report & 659 & $\begin{array}{l}\text { Problem gambling severity was positively associated with (i) } \\
\text { how much gamblers talked about betting with other people } \\
\text { prior to bet placement and (ii) how often online betting } \\
\text { functions such as 'cash out' were utilised and time spent } \\
\text { betting. In-play sports betting was found to be more prev- } \\
\text { alent amongst problem gamblers when compared to } \\
\text { moderate-risk gamblers, low-risk gambler and non-problem } \\
\text { gamblers. }\end{array}$ \\
\hline Nelson et al. (2008) & $\begin{array}{l}\text { Behavioural } \\
\text { tracking }\end{array}$ & 567 & $\begin{array}{l}\text { Bettors who utilised a self-limit (SL) feature were more likely } \\
\text { to prefer in-play betting on match outcomes opposed to } \\
\text { betting on fixed-odds events. Bettors who used the SL } \\
\text { feature placed more bets per day but wagered less money } \\
\text { per bet on in-play betting than non-SL players. After } \\
\text { utilising the SL feature, subscribers reduced gambling ac- } \\
\text { tivity. However, for sports-betting gamblers, the frequency, } \\
\text { amount and percentage-loss of wagers did not change. }\end{array}$ \\
\hline $\begin{array}{l}\text { Parke and Griffiths } \\
\quad(2007)\end{array}$ & Theoretical & $\begin{array}{l}\text { Not } \\
\text { appli- } \\
\text { cable }\end{array}$ & $\begin{array}{l}\text { It was theorised that because of the change in structural } \\
\text { characteristics that in-play gambling provided that in-play } \\
\text { betting may contribute to problem gambling because of (i) } \\
\text { an increase in perceived skill, (ii) within-session chasing on } \\
\text { the same match or event and (iii) by making the sporting } \\
\text { events more interesting and/or exciting. }\end{array}$ \\
\hline $\begin{array}{l}\text { Xuan and Shaffer } \\
\text { (2009) }\end{array}$ & $\begin{array}{l}\text { Behavioural } \\
\text { tracking }\end{array}$ & 226 & $\begin{array}{l}\text { Prior to closing their gambling accounts, self-identified in-play } \\
\text { betting problem gamblers, whilst experiencing increasing } \\
\text { losses, were more likely to try to recoup their losses by } \\
\text { increasing their stake per bets on events that had less risky } \\
\text { (i.e., shorter) odds. A decrease in gambling frequency } \\
\text { in-play problem bettors was observed prior to account } \\
\text { closure. }\end{array}$ \\
\hline
\end{tabular}

\section{Behavioural Markers for At-Risk Gambling}

Studies using the bwin dataset have also aimed to identify problem gambling in its early stages. When players surpass what is considered a normal level of gambling activity, they may be categorised at risk of developing gambling problems or already engaged in too much gambling. Some research has utilised behavioural tracking data in an attempt to identify such thresholds with the aim of detecting markers for problem gambling at the earliest opportunity.

Braverman and Shaffer (2010) examined whether several gambling characteristics could serve as predictors of future gambling-related problems using a sample of 530 in-play sports bettors who went on to close their accounts due to gambling-related problems after a 1-month period. Four characteristics were considered when gamblers initially started betting: (i) 
gambling frequency (number of betting days), (ii) gambling intensity (number of bets per day), (iii) gambling trajectory (the tendency to increase or decrease the amount of wagered money) and (iv) gambling variability (the standard deviation of wagers). They found that gamblers who were more likely to close their online betting account due to gambling-related problems initially demonstrated a higher pattern of high variability, high intensity, and high variability of wager sizes when in-play gambling than the gamblers who did not report gambling-related problems upon closing their account. Although it is not possible to determine why there was a relationship between high wager intensity and variability and gambling-related problems, it was speculated that external factors (e.g., availability of time, social relationships, or money resources) influence problem gamblers more than 'social gamblers'. Furthermore, the variability in in-play wagers may be indicative of gamblers' desire to stop or to control their impulses (Braverman and Shaffer 2010). Although this study focused on the behaviour of inplay bettors, it was noted that some participants engaged in very little in-play betting during their first month or during the 2-year gambling period. It is possible that these bettors participated in other gambling activities (e.g., fixed-odds betting) and that these other ways of gambling contributed to account closure (Braverman and Shaffer 2010). Another limitation of this study is that it relies on account closers' self-reported gambling-related problems as an indication of actual gambling-related problems. Subsequently, there is no clinical evidence of the participant experiencing gambling-related problems.

Brosowski et al. (2012) investigated the associations between participation in different gambling types and at-risk gambling. They analysed behavioural data from 27,653 bwin subscribers that included the use of eight gambling products by players over a period of 7 months. They found that $60 \%$ of gamblers took part in more than one form of gambling and that gambling involvement levels, including gambling on multiple game types, were predictive of gambling-related problems. Engaging in in-play betting or poker were significant predictors of at-risk gambling after controlling for multiple game involvement. One limitation of this study is that data were not collected to confirm whether the participant gambled with any other provider or whether they were the sole user of the account. Secondly, it is not known what marketing interventions were offered by bwin around the time of recruitment. Brosowski et al. (2012) suggest that it is possible that a marketing intervention may have artificially increased the sample with bettors only interested in bonus incentives, who then decreased their betting activities after taking advantage of the bonus offers on subscription to the site.

Braverman et al. (2013) carried out a study attempting to identify behavioural markers that can be used to predict the development of gambling-related problems. Approximately half of the 4056 participants had been received what was termed a 'responsible gambling (RG) flag' by bwin. Reasons for receiving RG flags included closing their account due to responsible gambling-related problems and/or displaying unusual financial and/or verbal behaviours (e.g., requesting a higher deposit limit). The other half of the sample consisted of subscribers who did not have an RG flag at the time of study. This was the control group $(n=2014)$, and they were matched by the date of their first deposit. The analysis identified two groups of online gamblers who had a higher risk of developing gambling problems. The first group engaged in multiple gambling activities and demonstrated a high wager variability on casino games in their first month on using the gambling website. The second group participated in two different gambling types and demonstrated high variability for in-play sports betting. One limitation of this research was the method used to describe betting behaviour. The difference in the number of bets and the stake size between the first and second half of the month were calculated and used this information to categorise the gamblers into one of three groups: stable, increasing, 
and decreasing. Braverman et al. (2013) suggest that other methods of categorisation may be proven useful in predicting gambling-related problems. Another limitation was that the bwin responsible gambling program is used as an indicator of gambling-related problems but has not been evaluated against clinical evaluation (Braverman et al. 2013).

LaPlante et al. (2014) reported that people who bet on in-play sports (as opposed to prematch betting) were more likely to experience gambling-related problems. In this study, 1440 online surveys were collected from bwin subscribers who completed the Brief Biosocial Gambling Screen (BBGS; Gebauer et al. 2010). These data were then analysed alongside online gambling patterns. After controlling for breadth (the number of games an individual plays) and depth (as measured by the number of days spent gambling) of gambling involvement, the study found a relationship between in-play betting and gambling-related problems remained. One limitation of this research was that it utilised an online self-report survey (the BBGS) to assess pathological gambling. An independent clinical validation of the selfreported BBGS assessment was not provided, and the BBGS is a relatively new screen that requires further validation. Therefore, the results were subject to limitations associated with self-report methodology (LaPlante et al. 2014).

Some studies have used the utilisation of online responsible gambling features by players on online gambling platforms to make inferences about online gambling behaviour including in-play betting. Gray et al. (2012) examined 2066 bwin subscribers who triggered an automated responsible gambling (RG) alert. Subscribers triggered RG interventions by engaging with bwin customer service representatives concerning various responsible gambling tools (e.g., account closure, voluntary self-exclusion, and deposit limits). When gambling behaviour of the bwin subscribers was compared to a group of control subscribers, indices of the intensity of gambling activity (e.g., total number of bets made, number of bets per betting day) for inplay sports bettors most differentiated those who had triggered the responsible gambling alert from the control group. A limitation of this particular study was that triggering an RG feature does not serve as a guaranteed indicator that the user has experienced a gambling-related problem (Gray et al. 2012; Griffiths and Auer 2016; Nelson et al. 2008). This supports previous research showing that those using responsible gambling tools such as limit-setting (Nelson et al. 2008) are more likely to engage in in-play betting than those who do not use such RG tools. However, if there is an association between engaging in in-play sports betting and disordered gambling, the direction remains unclear (Gray et al. 2012). A limitation of using players who set voluntary limits as a population of study is that they may not be representative of all subscribers with problems. Only a small subset of people with gamblingrelated problems actively seek help for that problem (Slutske 2006); therefore, the researchers are limited with the conclusions that can be proposed about gambling-related problems from those who do not seek help (Nelson et al. 2008).

Xuan and Shaffer (2009) reported on the behaviour of in-play gamblers using the bwin dataset. The gambling behaviour of a sample of 226 bwin subscribers who later went on to close their account was compared to a control group of 226 subscribers. In-play wagering patterns were a significant behavioural marker for players who then went on to close their betting account. Those gamblers with account closures demonstrated higher stakes per bet and increased monetary losses but a more conservative betting strategy prior to closing their account. Studies by Braverman and Shaffer (2010) and Xuan and Shaffer (2009) complement the findings of one another in respect to identifying in-play betting behaviours that act as indicators to future gambling-related problems gambling. However, there are limitations for the methodology that was used. Behaviour was only analysed for players who closed their 
accounts during a select period, a very small proportion of the total bwin sample (1.11 and $0.47 \%$ respectively). Only in-play betting behaviour was investigated, and it has been noted that it is likely that these gamblers also gamble on other games (e.g., fixed odds betting), and so, other betting activity may have contributed to the closing of the account.

Broda et al. (2008) compared gambling behaviour of those who exceeded deposit limits (i.e., a voluntary limit set on the amount that can be deposited onto an online gambling account) with those who did not within a sample of 46,840 bwin subscribers. Their period of analyses was longer than that of Nelson et al. (2008) - a 2-year period as opposed to 18 months. Broda et al. (2008) found that people who received a notification advising them that they had exceeded their deposit limit demonstrated a higher involvement in sports betting (as measured by bets per day and stake size) than players who had not exceeded their deposit limit. However, only a small percentage of players $(0.3 \%)$ exceeded deposit limits. However, this was the only study that reported no difference in betting behaviour between players who placed fixed-odds bets and those who placed live action (in-play) bets. However, one major limitation of the study was that although the deposit limit amount that led to issuing a notification message may differ between participants, it was not possible to analyse whether different limits were associated with different effects on gambling behaviour because these data were not available (Broda et al. 2008).

\section{Self-Reported Gambling Behaviour}

A few studies utilising self-report methods have been carried out with the aim of attempting to identify behavioural, psychological and socio-demographic predictors of sports gamblers (including those who bet in-play). Within a sample of 1816 Australian sports gamblers, more impulsive sports gamblers were found to have higher problem gambling severity scores and were more likely to place a higher number of their bets on impulse in-play sports gambling, as opposed to betting on pre-match outcomes (Hing et al. 2017a). However, the authors noted that causal directions were unclear because it may be that placing impulsive in-play bets leads to the development of gambling problems, or conversely, that at-risk and problem gamblers are more likely to place impulse bets in-play. Therefore, in-play betting may be more likely to promote impulsive behaviour, although there is currently no empirical evidence available to support this relationship (Lopez-Gonzalez and Griffiths 2017).

Hing et al. (2016) carried out a study that attempted to identify demographic, behavioural and normative risk factors for gambling problems amongst a sample of 639 Australian sports bettors. Sports bettors who engaged in more than one type of gambling showed higher problem gambling severity (measured using the Problem Gambling Severity Index; Ferris and Wynne 2001). Higher problem gambling severity was associated with a less planned, more impulsive approach to sports betting, particularly in-play sports betting. People who planned and researched their bets prior to an event were found to have significantly lower PGSI scores than those who did not. Limitations of this study include its use of self-report data that is subject to recall, social desirability and other biases, and that its use of cross-sectional design does not allow for the determination of causality (Hing et al. 2016).

Lopez-Gonzalez et al., 2018) explored the association between the use of new structural characteristics of online betting and gambling severity within a sample of 659 Spanish bettors who had bet on sports during the previous 12 months. They examined live in-play betting, the cash out in-play feature, fantasy sports gaming, location of betting and device or platform used to make a bet. In-play betting was reported to be associated with those who were categorised as 
problem gamblers. They also reported that those categorised as problem gamblers used the inplay cash out feature more than those who were not. The authors provided several limitations of the study. The first being that it relied on self-report data which can be subject to biases, including memory recall and social desirability. Secondly, the study employed a crosssectional design, which did not allow for casual implications to be drawn from the results between the four different variables. Finally, there was a chance that out of those who received the survey request, those who demonstrated a greater degree of participation in betting activities were more interested in responding to the survey and resulted in a larger proportion of problem gamblers in the sample (Lopez-Gonzalez and Griffiths 2018).

\section{Theoretical Papers on Gambling Behaviour}

A number of scholars in the gambling studies field have argued that structural characteristics of gambling, including activities with higher event frequencies, are associated with problem gambling (Griffiths and Auer 2013; Harris and Griffiths 2017). In short, those activities that can be gambled on continuously such as slot machines (which can have event frequencies of up to 30 times a minute on an online slot machine) tend to have a much higher association with problem gambling than activities such as a bi-weekly lotto game (with an event frequency of twice a week) (Griffiths and Auer 2013). In relation to in-play betting, Parke and Griffiths (2007) were the first scholars to speculate that in-play betting may contribute to prolonged, excessive, un-planned, or problem gambling due to (i) a growth in 'perceived skill' (through studying, analysing or spectating the betting event), (ii) chasing losses/winnings on the same or different sporting event by placing further bets during the event and (iii) by making the sporting event more stimulating or exciting.

Papers by Griffiths and Auer (2013) and Lopez-Gonzalez and Griffiths (2017) made a number of similar observations. Previously, bet duration (the time from placing the bet, until its settlement) was fixed. However, bet durations can now be amended via in-play cash out features (Lopez-Gonzalez and Griffiths 2017). In-play betting utilising cash out features have the potential to make sports bettors more vulnerable to cognitive bias (Lopez-Gonzalez and Griffiths 2017). In the past, sports betting was typically a discontinuous form of gambling with the vast majority of sports bettors gambling weekly on the outcome of a particular event (e.g., a football match). However, some papers have specifically argued that in-play betting and use of the cash out feature now allows sports betting to be a continuous form of gambling (Griffiths and Auer 2013; Lopez-Gonzalez and Griffiths 2017). This has radically changed the traditional sports betting market which was once a discontinuous (low-risk) gambling activity to a more continuous (high-risk) gambling activity. In-play sports bettors who experience gambling-related problems may feel more inclined to engage in less planned, impulsive, and immediate forms of gambling and the time between bet placement and the reward (or lack of) is greatly shortened (Parke and Griffiths 2007; Griffiths and Auer 2013).

A paper published by Lopez-Gonzalez and Griffiths (2017) is the only paper that explicitly discusses the implication of in-play cash out sports betting features. They suggested that one of the implications of cash out in relation to problem gambling is that there is a conception of gambling on sports as an investment, like that of trading on the stock market. This was then confirmed empirically showing that sports betting advertisements contribute to selfperceptions of bettors as specialists of sports, promoting game analysis to beat gambling companies (Lopez-Gonzalez et al., 2017a, b, c, d). The notion that the bettor can view themselves as a professional that can improve their probability of winning may serve as a 
motivating factor to gamble (Lopez-Gonzalez and Griffiths 2017). Problematic online bettors have been found to consider themselves to be semi-professional gambler, and in the case of horse racing bettors, they are more likely to self-report being a professional gambler (Hing et al., 2017a, b).

There have also been a couple of important position papers in the grey literature concerning in-play betting (see Table 2). The Department of Broadband, Communications and Digital Economy in Australia commissioned the Allen Consulting Group (2012) to provide advice on issues relating to in-play betting. At the time the report was produced, it stated that there was no academic literature on the prevalence of the in-play betting in Australia. The report noted that inplay betting had grown in popularity amongst the European betting industry, but this growth is not matched in Australia due to legal betting restrictions. Based on discussion with gambling providers, in Australia, it was reported that the amount of people using an in-play betting service is small, but still part of the gambling market (Australian Interactive Gambling Act 2001).

The UK Gambling Commission (2016) produced a report in order to set out their position in relation to in-play sports betting. Their position is considered in the context of the potential risk that in-play betting may pose to the three licensing objectives set out by the Gambling Act (2005). These are "(a) preventing gambling from being a source of crime or disorder, being associated with crime or disorder or being used to support crime, (b) ensuring that gambling is conducted in a fair and open way, and (c) protecting children and other vulnerable persons from being harmed or exploited by gambling." (Gambling Act 2005, p. 19). One factor that the Gambling Commission considered was whether this particular gambling activity could be harmful. In 2009, the Gambling Commission previously reported that there was no evidence to suggest that in-play betting posed a greater specific risk of causing gambling-related hard than other forms of online gambling. In the 2016 report, they noted that since 2009 , more research has been carried examining potential associations between inplay betting and gambling-related harm.

The Gambling Commission report (2016) suggested that there could be a greater risk of harm from gambling for those who participate in in-play sports betting compared to those who participate in other forms of gambling. The first example that the Gambling Commission provided was that in-play gambling provides the opportunity to place more frequent bets on the same event, and some research suggests that there is an association between this increased opportunity, or to be 'rewarded' with an increased chance of experiencing gambling problems

Table 2 Grey literature papers that discuss in-play sports betting

\begin{tabular}{|c|c|c|c|c|}
\hline $\begin{array}{l}\text { Author/ } \\
\text { organisation }\end{array}$ & Title & Country & Methodology & Summary \\
\hline $\begin{array}{l}\text { The Allen } \\
\text { Consulting } \\
\text { Group } \\
(2012)\end{array}$ & $\begin{array}{l}\text { Research for the } \\
\text { Review of the } \\
\text { Interactive } \\
\text { Gambling Act } \\
2001 \text { Online } \\
\text { Gambling and } \\
\text { 'In-the-Run' } \\
\text { Betting }\end{array}$ & Australia & $\begin{array}{l}\text { Commissioned } \\
\text { report }\end{array}$ & $\begin{array}{l}\text { It is not currently legal to place an } \\
\text { in-play bet online in Australia, } \\
\text { and no academic research has been } \\
\text { published to evaluate in-play sports } \\
\text { betting. }\end{array}$ \\
\hline $\begin{array}{l}\text { Gambling } \\
\text { Commission } \\
(2016)\end{array}$ & $\begin{array}{l}\text { In-play } \\
\text { (in-running) } \\
\text { betting: position } \\
\text { paper }\end{array}$ & UK & $\begin{array}{l}\text { Self-commissioned } \\
\text { report }\end{array}$ & $\begin{array}{l}\text { The report acknowledges that in-play } \\
\text { betting may pose some issues } \\
\text { relating to (i) fairness and } \\
\text { transparency of the betting, (ii) } \\
\text { integrity of the betting, and (iii) risk } \\
\text { of harm within the betting medium. }\end{array}$ \\
\hline
\end{tabular}


(Griffiths 2012). Secondly, they cited Australian research from Hing et al. (2016) demonstrating an association between tendencies to place a higher number of in-play bets with an increased risk of harm from gambling. Finally, they cited figures from a Gambling Prevalence Report (Gambling Commission 2017) which indicated that $27.4 \%$ of online gamblers who bet in-play were classified as problem gamblers, compared to $10.9 \%$ of all online gamblers and $5.4 \%$ of online gamblers who do not bet in-play. Consequently, it was noted that those who bet in-play are at greater risk of harm from gambling than those who do not bet in-play. The report concluded that based on the evidence review, the UK's current regulatory system of in-play betting was sufficient and that no further controls were required at the time of writing.

\section{Current In-Play Sports Betting Products}

At the time of the present scoping review, three different online in-play betting features are currently being used by online sports bookmakers (cash out, 'Edit my Acca', and 'Edit my Bet'). There are also two other features were identified that at the time of writing were in the process of being introduced and/or developed ('Add 2 Bet' and 'betting using GPS tracking'). These features are described in detail below:

'Cash Out' The first online sports betting provider to offer the option to cash out bets was William Hill in 2012 (Gaming Intelligence 2014). Since the introduction of this in-play product, many European online operators have followed suit and made this product an available feature on their website via a desktop or mobile device. Betfair provided the following description of the in-play cash out feature:

"Cash Out lets you take profit early if your bet is coming in, or get some of your stake back if your bet is going against you - all before the event you're betting on is over. Cash Out offers are made in real time on your current bets, based on live market prices. Whenever you are ready to Cash Out, simply hit the yellow button. Cash out is available on singles and multiples, on a wide range of sports, including football, tennis, horse racing, and many more! You can Cash Out of bets pre-play, in-play, and between legs" (Betfair 2017).

There are several different types of cash out. Operators such as Bet365 offer the option to 'partially cash out a bet' (the gambler can choose how much of their bet they wish to cash out) and 'auto cash out' - the gambler can select a value and if this value of the bet is reached, then it is automatically cashed out (Bet365 2017a).

Edit My Acca (Accumulator Feature) The second identified in-play betting product that has been introduced to the sports betting market is the 'Edit my ACCA' feature. In May 2016, Ladbrokes introduced this feature to the in-play betting market (Ladbrokes 2017). This feature allows gamblers to remove selections from their accumulator after the bet has been placed and in some instances after the selected event has started. The betting slip is then revised to feature the amended selections and a new potential return amount. This can be done online or via a mobile device (Ladbrokes 2017).

Edit My Bet Thirdly, 'Edit my bet' is an in-play betting feature that was introduced by Bet365 in January 2017 (Bet365 2017b). The 'edit bet' feature can be used by gamblers to 'unsettle straight accumulators' before matches have started or whilst they are in-play (Bet365 2017b). The feature can also be used for to swap single bets for new bets, and the gambler is given a new bet selection valued at Bet365's cash out price to reflect live market/game odds for the original bet. 
Add2Bet 'Add2Bet' is one of the latest betting products to be introduced to the betting market, and provided by SBTech (2017). This new live betting feature is aimed at both players and gambling operators. Add2Bet has been described as "a mobile-focused enhancement, designed around simplicity and ease-of use" (SBTech 2017, p. 1). This new live betting feature allows gamblers the option to instantly use the cash out value of an open bet to create a new bet type - a new double, treble, or acca (accumulator) - by combining it with new selections. It has been advertised as giving players more control over their betting and appeals more effectively to millennials (SBTech 2017). During initial trials of the feature, (which is yet to go live at the time of writing this scoping review), it was found that those aged under 35 years were early adopters of the feature, "with players from this age group trying Add2Bet after seeing it just twice on average, whereas older users waited until they had viewed it an average five times" (SBTech 2017, p. 1). Of the sample included in testing the new feature, it was found that 7\% of English Premier League football live bets utilised the Add2Bet to edit an existing live bet. Furthermore, almost $70 \%$ of player who used cash out for approximately $40 \%$ of their betting activity placed a bet using the new feature.

Betting Using GPS Tracking The final in-play betting feature identified is betting using GPS tracking technology. According to online news stories, UK betting providers are preparing the introduction of in-play horserace betting that includes the use of global positioning system (GPS) technology (Streeter 2017). Gamblers looking to place a bet on a live horse racing event will be able to view the horse positions within the race (which may have previously been undetermined due factors such as the speed of the race, or confusion over the distinguishing jerseys worn by the jockeys) using the GPS tracking system. The aim of this is to aid online sports betting customers to make a decision. Gambling operators Paddy Power and Bet365 are already manually offering in-play wagering markets on horse racing markets. However, it has been proposed that this feature will have an average accuracy of the horse's position within $0.1 \mathrm{~m}$, all delivered within a maximum time lag of $0.1 \mathrm{~s}$. The UK racing sports turnover in 2016 generated $£ 5.64$ b; therefore, it has been predicted that this new feature will increase profits for online gambling companies (Wood 2017).

\section{In-Play Sports Betting Products on Online Bookmakers' Websites}

Of the 513 online sports betting websites reviewed, it was possible to access 338 of these at the time of carrying out the research. Reasons for not being able to access specific bookmaking sites included that the site was (i) no longer active, (ii) not possible to access from the UK due to betting regulations, or (iii) blocked for security reasons.

Of the 338 websites accessed, 88 of these (26\%) offered at least one in-play betting feature (see Appendix Fig. 1). All 88 online gambling websites offered 'full' cash out on selected markets, and 29 of the websites also offered the option of 'partial cash out'. Two websites offered 'auto cash out', where cash out 'rules' can be created with no further input from the bettor. Once a selected value reached, then the bet is automatically cashed out. Website accessibility determined by specific device type was categorised into two groups: (i) desktop (a computer that is suitable for use in one location) and (ii) mobile (a device that can be used on the move such as a smartphone, laptop or tablet). Three gambling websites only allowed cash out to be accessed via a desktop computer or laptop and one website via a mobile device only (e.g., a smartphone device, laptop, or tablet computer). A total of 77 sites offered the cash 
out facility via desktop or mobile device, and two sites allowed bets that were placed in a landbased betting shop to then be cashed out via a desktop or mobile device.

In terms of bet types that were able to be cashed out, the most commonly offered amongst those that provided in-play betting was single and accumulator bets (58 websites). An accumulator bet, also known as a multiple or parlay bet, is a single bet that links together more than one bet and is dependent on each individual bet being successful in order to result in an overall winning bet. Eight of the websites only allowed for single bets to be cashed out; one website stated that 'all bet types' could be cashed out, and 22 of the websites viewed did not explicitly state what bet types could be cashed out. In terms of named sports that were eligible for the cash out facility, football (soccer) was the most popular. Three of the sites only offered cash out to football bets, and 23 allowed football bets to be cashed out with a range of other sports available also. A majority of the websites visited that provided in-play betting $(n=54)$ did not explicitly state which sports cash out would be available for. In terms of market eligibility for cash out, for example 'full time result, 'number of goals' and 'both teams to score', 58 websites did not explicitly state which markets were available for cash out, whereas 30 websites did. One sports betting operator (Ladbrokes) operated the in-play betting feature 'Edit my Acca' feature (described in the previous section), and one operator (Bet365) offered the in-play feature 'Edit my Bet' (also described in the previous section).

\section{General Discussion}

The present scoping review is a first attempt to scope the literature and present information on what is known about in-play sports betting. To date, the most commonly used empirical method of investigating in-play gambling behaviours has been via the use of behavioural tracking data (although all of this has come from the same bwin dataset to date). Research published using the bwin dataset has reported that engaging in in-play gambling appears to be an important marker for gambling-related problems (LaBrie et al. 2007; LaPlante et al. 2008; Nelson et al. 2008). These studies described gambling-related behavioural factors associated with highly involved sports bettors (e.g., number of bets and the total amount wagered) and identified a sub-group of bettors who maintained a high involvement in online gambling via in-play betting (LaBrie et al. 2007; LaPlante et al. 2008). Other studies found that participation in in-play sports betting is an independent predictor of problem gambling severity when gambling involvement is controlled for (Brosowski et al. 2012; Xuan and Shaffer 2009). It was also found that gamblers who utilised an online provider's limit setting tool was more likely to engage in in-play betting than other forms of gambling (Gray et al. 2012; Nelson et al. 2008). After setting a voluntary limit, those who previously participated in fixed-odds and in-play sports betting were more likely to stop betting in-play than to stop betting on fixed-odds selections (Nelson et al. 2008). Nelson et al. (2008) suggest that this could indicate that the players consider in-play betting to be more of a risk. Overall, the reviewed studies suggest that multiple, frequent and larger in-play bets appeared likely indicators that differentiated high-risk sports bettors from lower risk sports bettors.

Although the results described using the $b$ win dataset allow for real-life gambling behaviour to be studied, they are not without limitations. Firstly, studies that utilise these datasets did not describe the gamblers' perceptions, clinical characteristics or the social consequences associated with their betting behaviour (Griffiths 2014; Shaffer et al. 2010). There was no information provided about users' income (Shaffer et al. 2010), and previous research has indicated that the impact of gambling is partially dependent upon the gambler's financial status; 
therefore, it is necessary to consider the amount spent gambling in relation to the amount of money that is available (Gray et al., 2012). Due the lack of psychosocial information about the meaning and consequences of gamblers, it is not possible to infer any clinical characteristics regarding the impact of internet gambling on the lives of individual subscribers (Griffiths 2014; Shaffer et al. 2010). One disadvantage of using online behavioural tracking is that internet gamblers may also gamble both online and in person, for example, at casinos or other gambling venues, and are unlikely to gamble at just one site (Wardle et al. 2011). Therefore, estimates of Internet gambling usage may not be an accurate representation of how much Internet subscribers gamble (Shaffer et al. 2010).

In relation to the self-report studies and academic theorising concerning in-play sports betting, researchers have constantly referred to the role of structural characteristics in the acquisition, maintenance and development of online gambling behaviour (Parke and Griffiths 2007) and have demonstrated an association between problem gambling and such features as event frequency, bet frequency and the speed of rewards (Griffiths 2012; Harris and Griffiths 2017). The gambling study literature has suggested that in-play sports betting may offer more of a risk to problem gamblers because it allows the option for high-speed continuous betting and requires rapid and impulsive decisions in absence of time for reflection (Hing et al. 2014a, 2014b, 2014c; Lopez-Gonzalez et al., 2017a, b, c, d; Nelson et al. 2008). Therefore, in relation to problem gambling, in-play betting offers structural factors that may contribute to the development of gambling-related problems. These characteristics include, but are not limited to bet frequency, event frequency, event duration, and pay-out frequency. Research has found in-play betting to be associated with people who were categorised as problem gamblers (Lopez-Gonzalez et al., 2018). Lopez-Gonzalez and Griffiths (2018) offered a potential explanation for this. More specifically, gamblers who are experiencing gambling-related problems may be inclined to place impulsive, less planned and readily available forms of gambling such as in-play. However, using the data from the present studies is not possible to identify a causal link between problem gambling and the use of different gambling types due to the correlational and cross-sectional nature of the few studies that have been carried out to date (Lopez-Gonzalez et al., 2018).

In relation to the primary data collected by the present authors visiting sports betting websites, the results demonstrated that $26 \%$ of online gambling websites offered at least one in-play betting feature. Given that previous empirical research has shown that games that offer a fast, exciting play and regular wins tend to be associated with problem gambling (Parke and Griffiths 2007), it could be that the structural characteristics of in-play betting features such as cash out facilitate problem gambling in vulnerable and susceptible individuals. Empirical research to date indicates that individuals characterised as impulsive sports bettors are more likely to bet on inplay matches than overall outcomes (Hing et al., 2017a). However, further empirical research is required in order to explore whether in-play betting plays a role in excessive or un-planned gambling. The UK Gambling Commission (2016) concluded that those who bet in-play are at greater risk of harm from gambling than those who do not bet in-play, but that no further regulation is currently required in the UK gambling market for in-play betting.

It has also been argued that the online aspect of gambling, a new situational as well as structural gambling characteristic of many gambling products, has changed the interaction between gamblers and gambling and may therefore increase the likelihood of gambling-related harm (McCormack and Griffiths 2013). The results of this current scoping study demonstrated that in-play betting features could be accessed via a mobile and desktop device in $87.5 \%$ of cases of the sport betting websites visited. This increased accessibility to online gambling 
platforms and the ease of interaction on platforms such as smartphones may accelerate the acquisition of maladaptive learned behaviours such as problem gambling (James et al. 2016). Again, further empirical research is required to explore whether technological advances and the ease of access to bet in-play increase the likelihood of a person experiencing gamblingrelated harm.

\section{Limitations}

A strength of scoping studies includes rigorous and transparent method of mapping evidence covered in a given field (Davis et al., 2009). However, practical issues relating to time and the fluid nature of the research area being explored must be considered, as well as the issue concerning the 'quality' of data collected (such as the data collected via visiting online gambling websites). With regards to the present study, the scoping study method allowed the possibility of illustrating the field of in-play betting product availability. This was achieved by reviewing many online gambling websites. The research team viewed as many websites available as possible. However, all available gambling websites were not reviewed. In total, 338 out of the 513 gambling were visited. This was due mainly due to country legislations which blocked accessibility to multiple online gambling websites.

Only a small number of empirical studies were identified during this scoping review. There was a large reliance on behavioural tracking data which does not explain why people are engaged in such behaviours. Additional limitations of using behaviour tracking research are related to the ethical issues of using gamblers' behaviour data without their awareness, and therefore, there is a lack of informed consent. This scoping study also identified very few selfreport studies, and no studies employing other methodologies were identified (e.g., experimental studies, observational studies).

The aim of the present scoping study was to review the contemporary literature empirically investigating or theorising about in-play sports betting and collate information about in-play sports betting features available to gamblers within the online sports betting market. Understanding factors that determine in-play betting behaviour, including understanding the risk factors for problem gambling amongst in-play sports bettors, is an important area of research given the continuing growth of the online sports betting industry. Overall, the research suggests that this way of gambling has the potential to be more harmful than other ways of gambling (e.g., gambling on fixed odds) because of the inherent structural characteristics. However, to date, there has only been one study that explores online sports betting behaviours in the context of specific in-play betting features (i.e., Lopez-Gonzalez and Griffiths 2018).

\section{Compliance with Ethical Standards}

Conflict of Interest The first author has no conflicts of interest. The second author has received funding for a number of research projects in the area of gambling education for young people, social responsibility in gambling and gambling treatment from Gamble Aware (formerly the Responsibility in Gambling Trust), a charitable body which funds its research program based on donations from the gambling industry. The first author also undertakes consultancy for various gaming companies in the area of social responsibility in gambling.

Ethical Approval All procedures performed in this study involving human participants were in accordance with the ethical standards of University's Research Ethics Board and with the 1975 Helsinki Declaration.

Informed Consent Not applicable. 


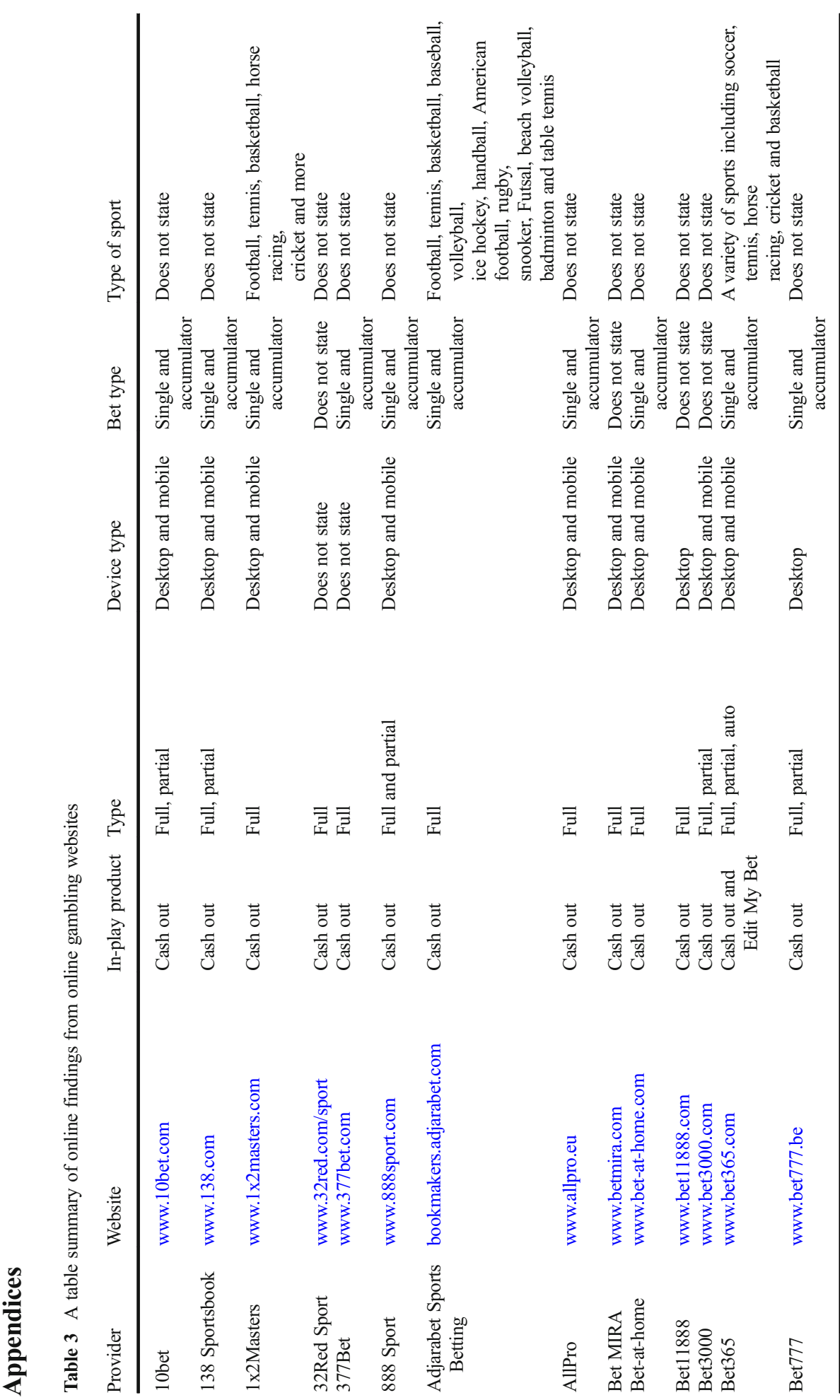




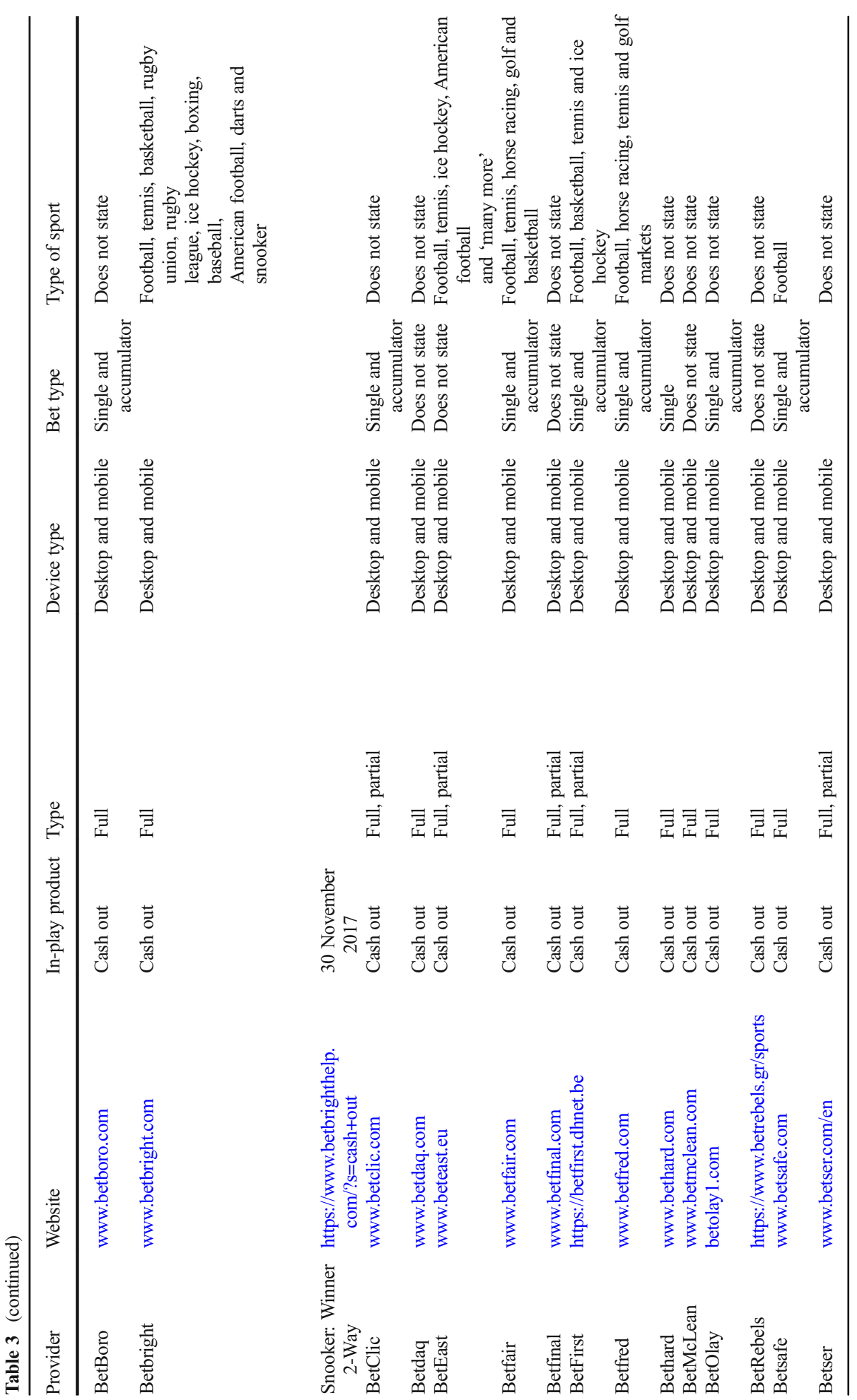




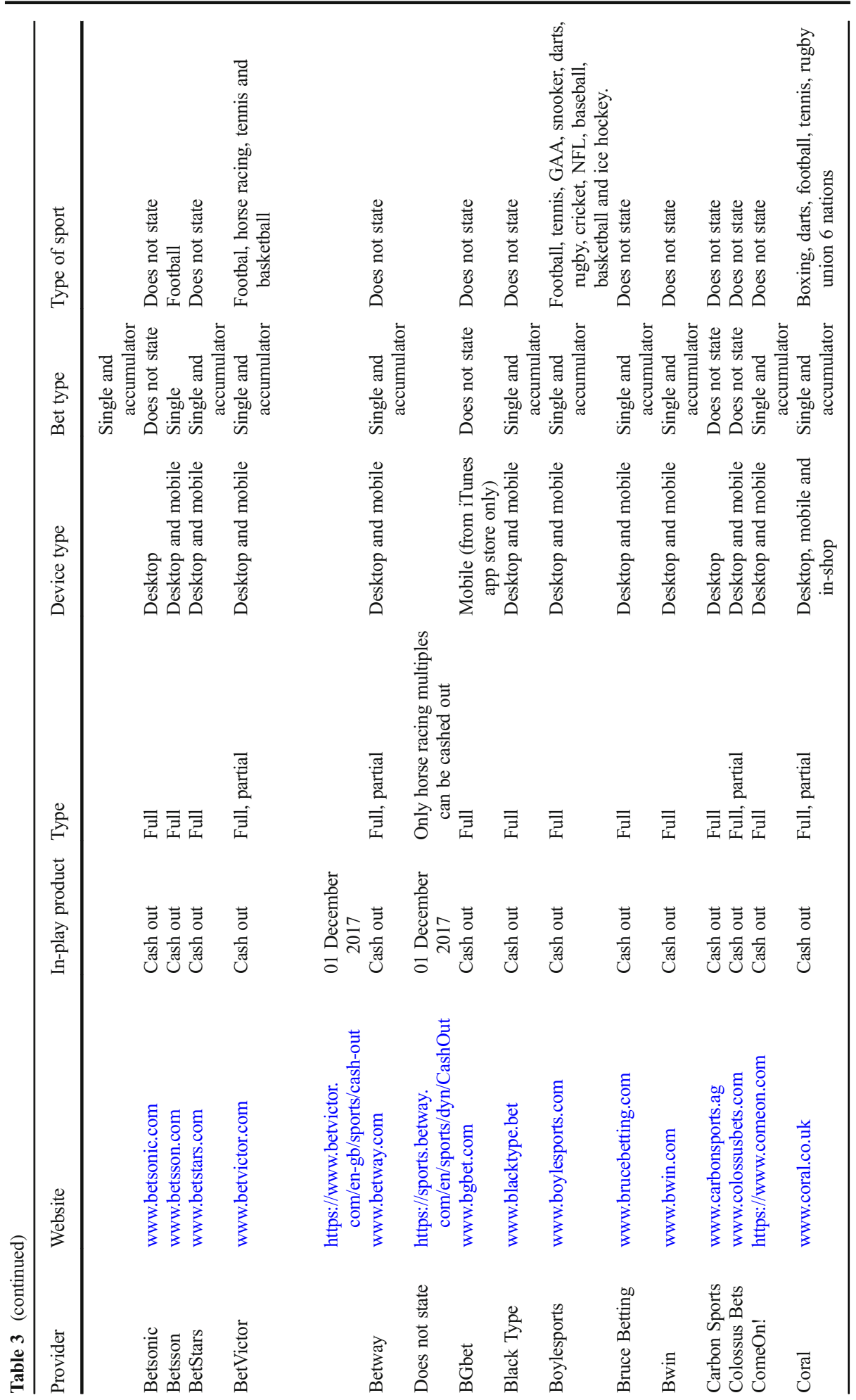




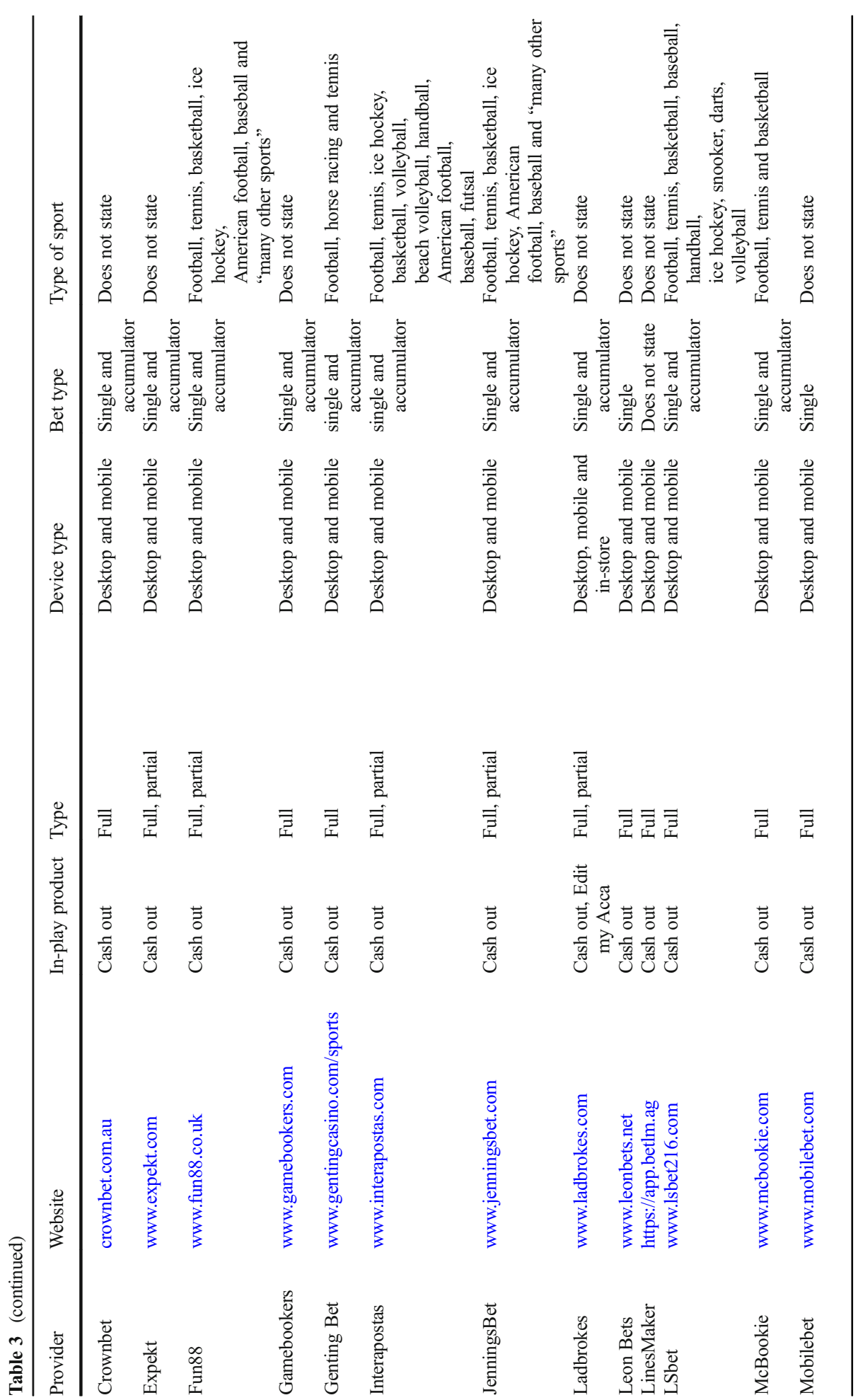




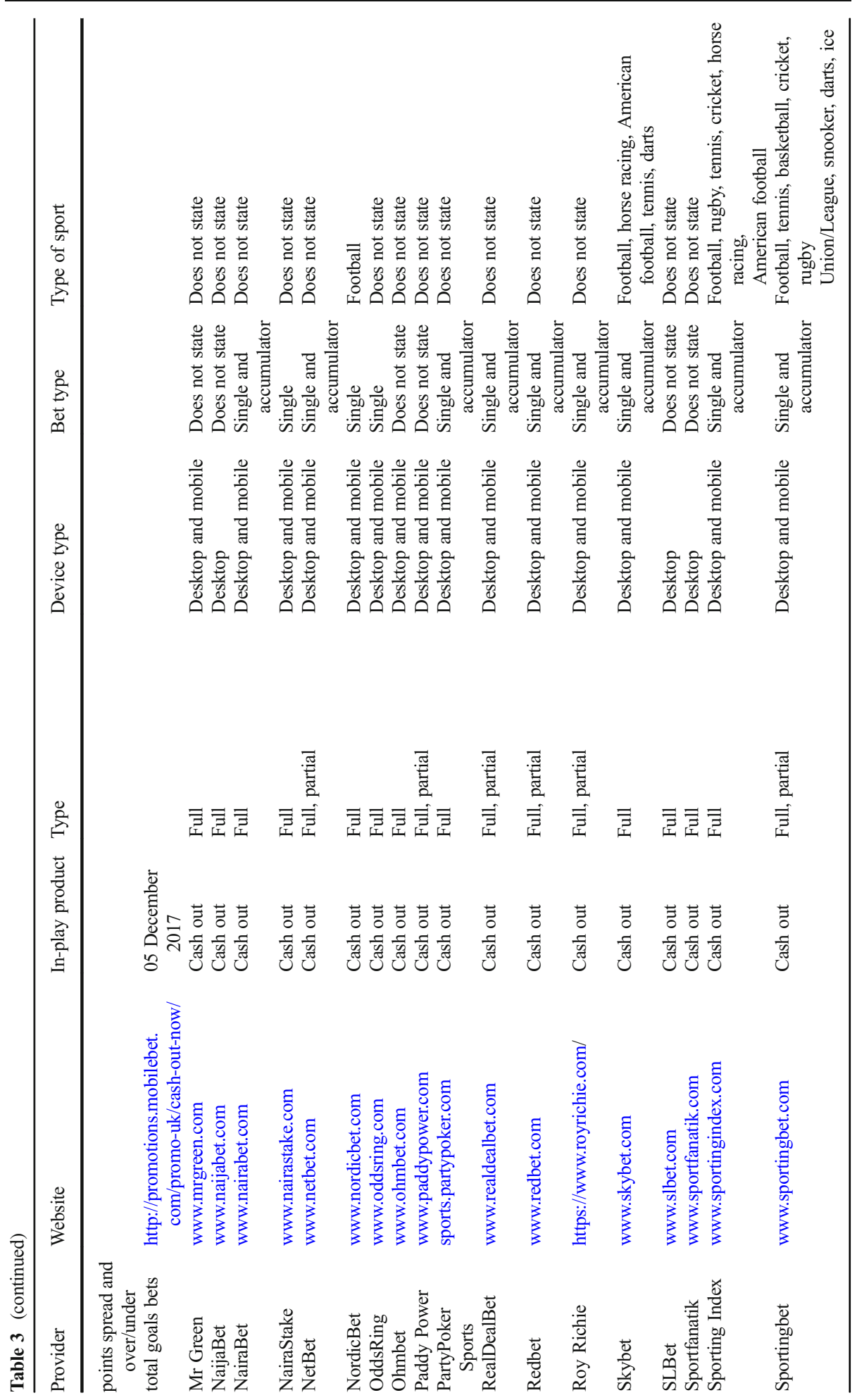




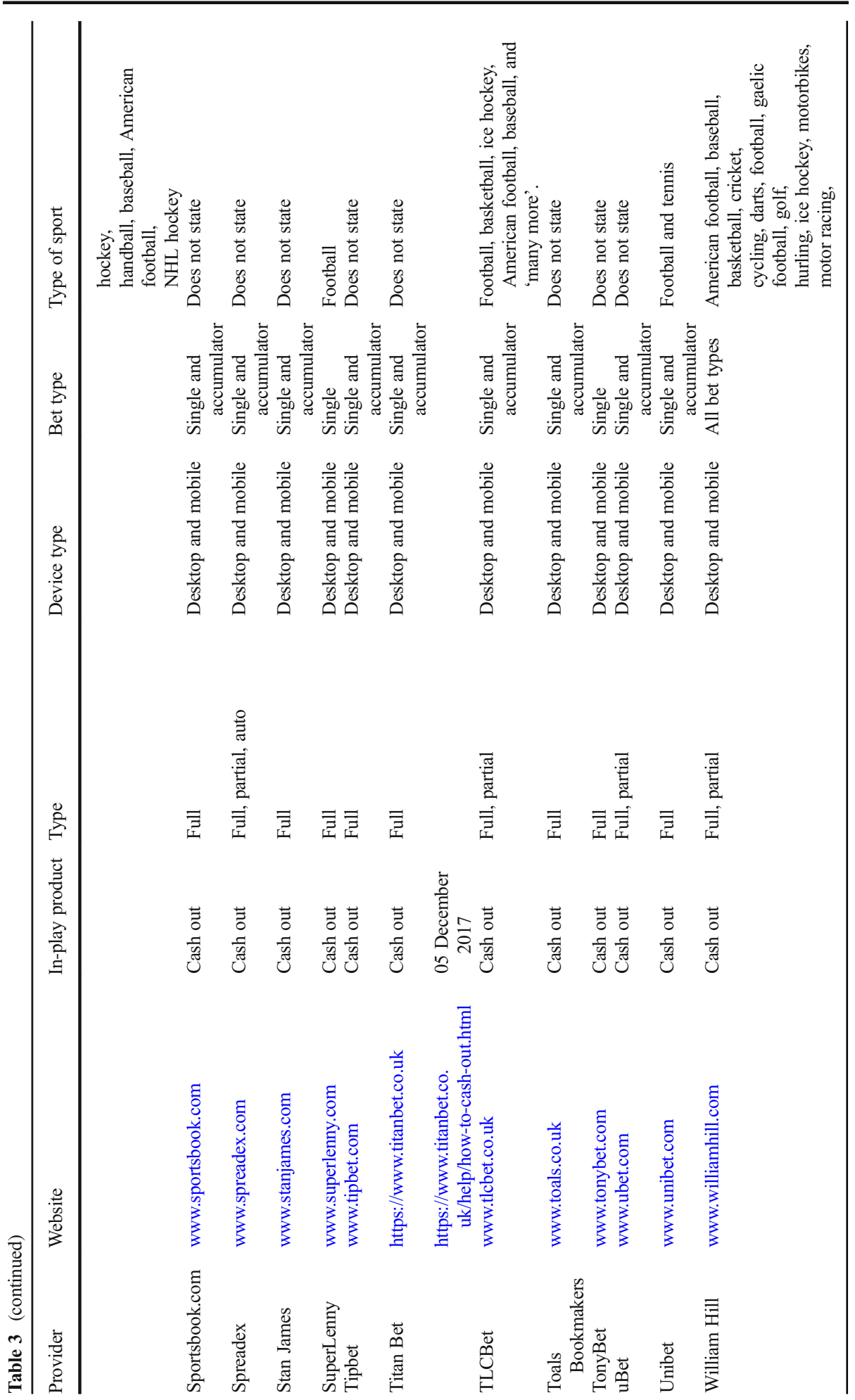




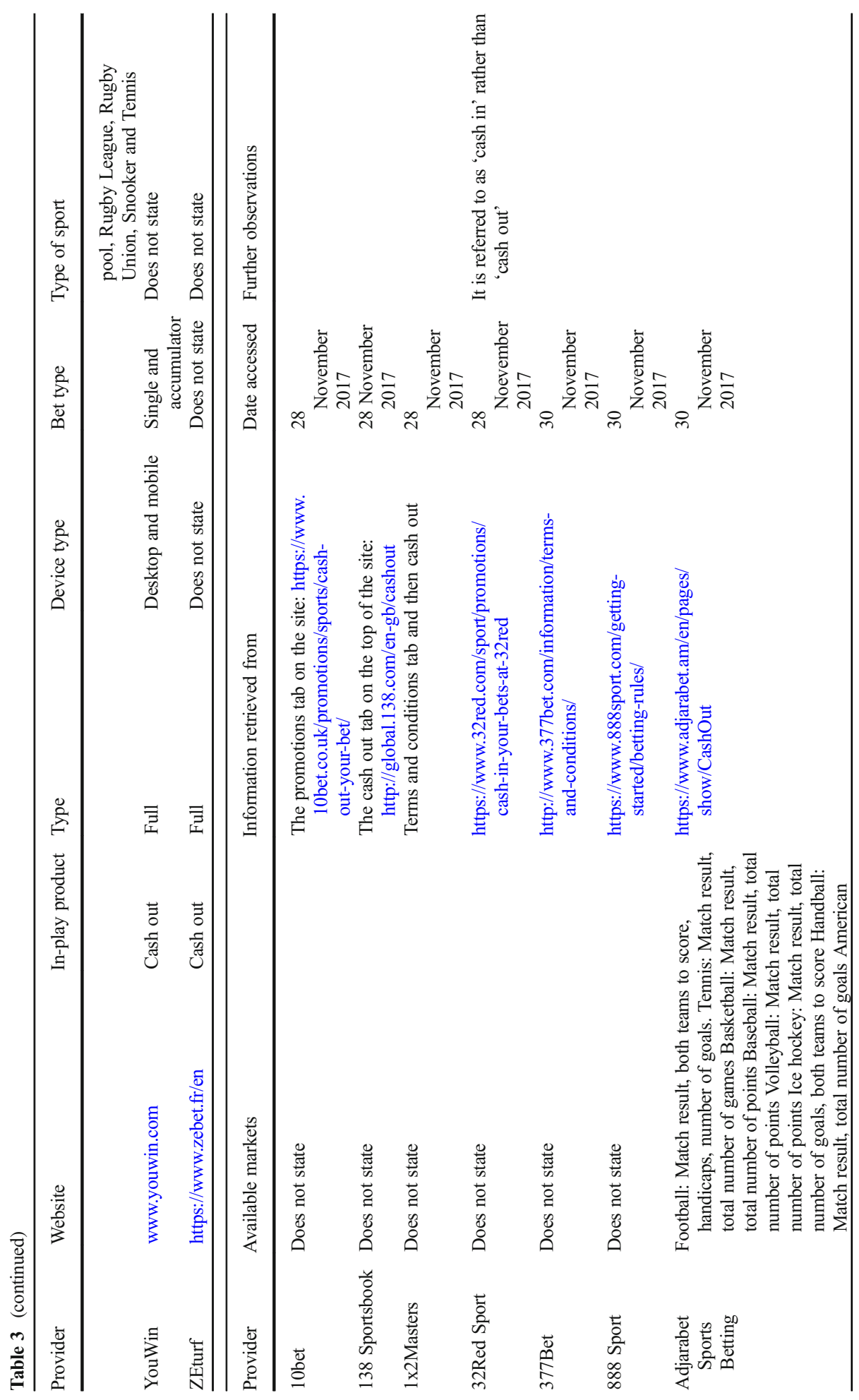




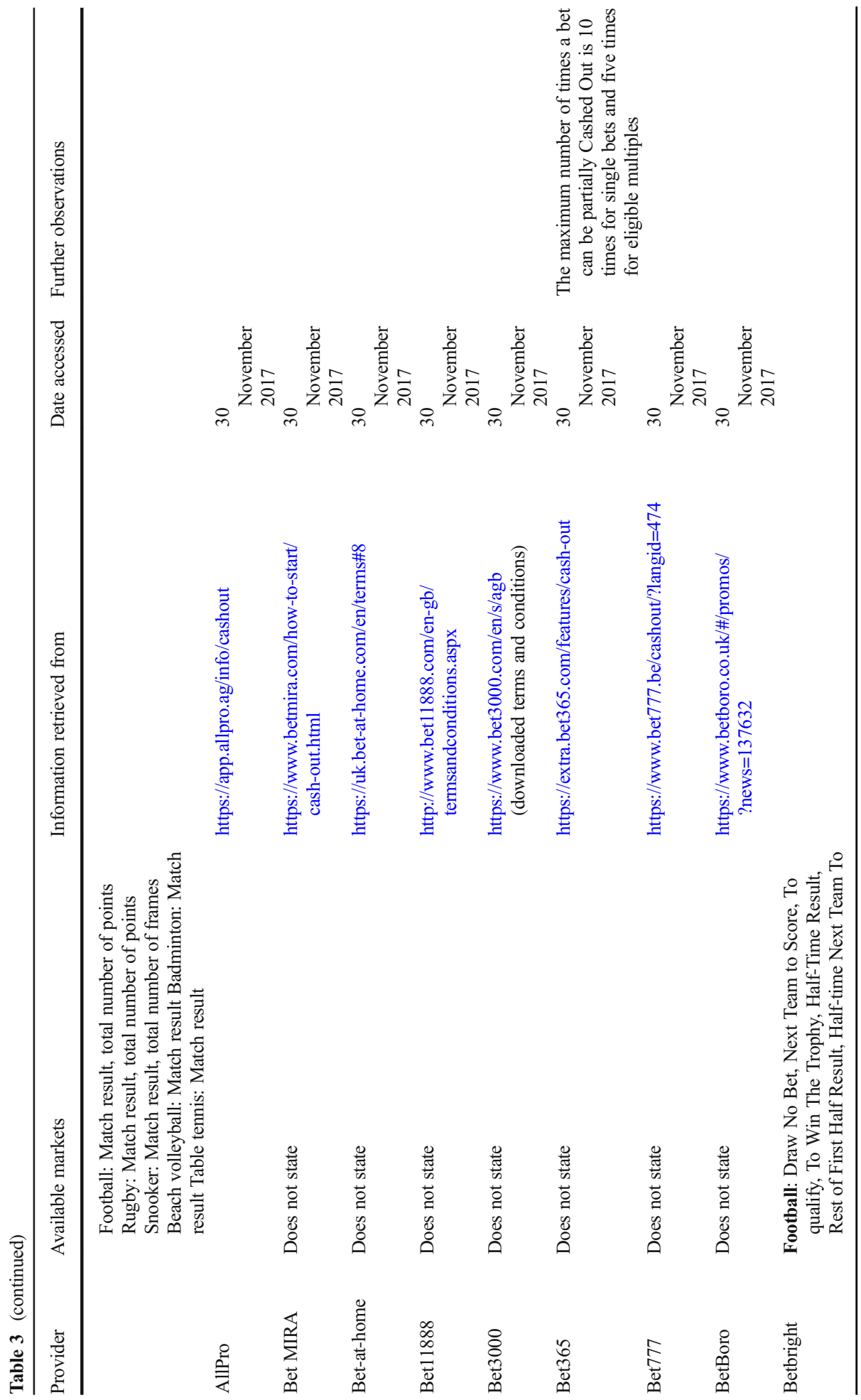




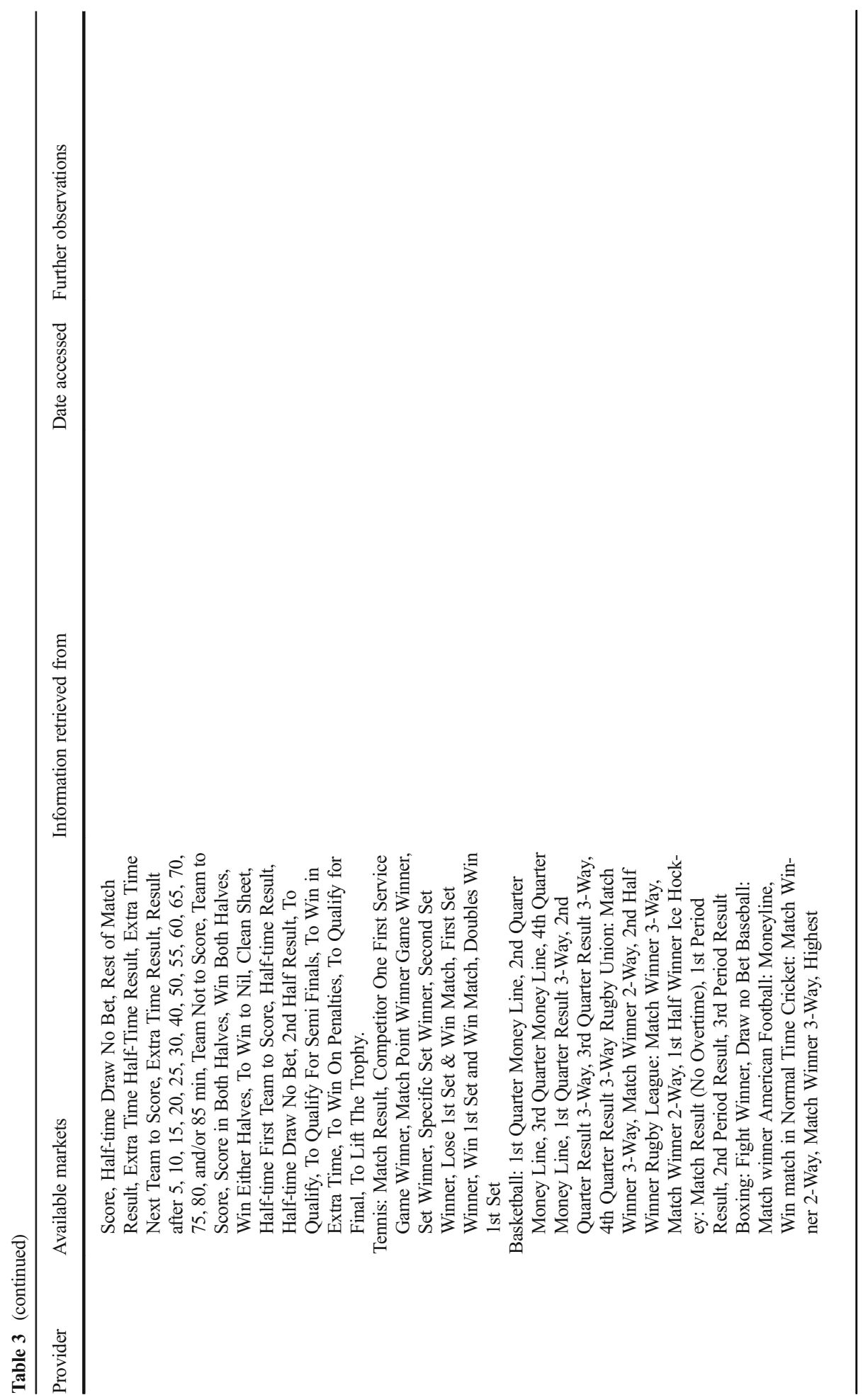




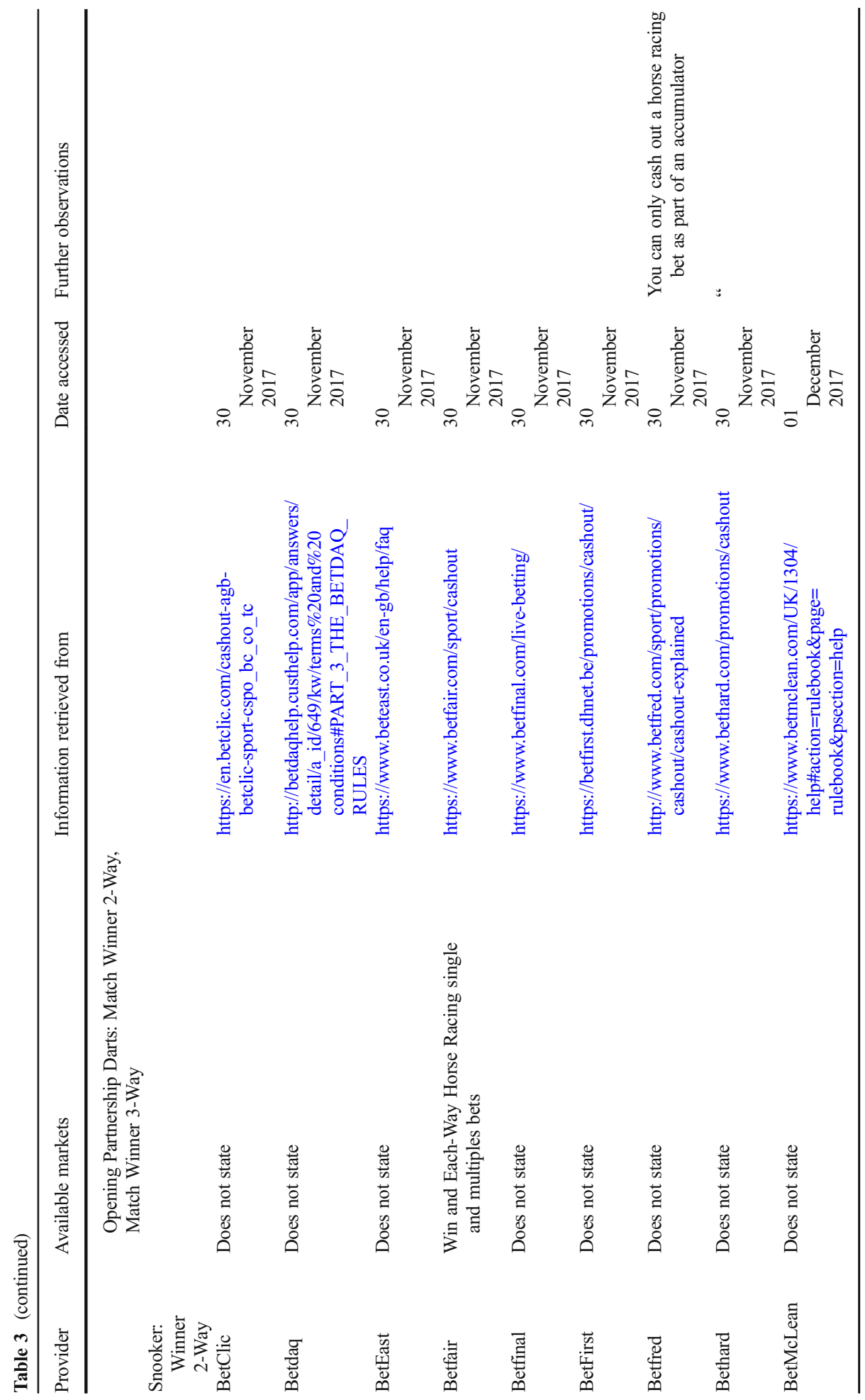




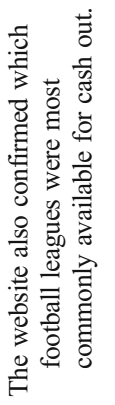

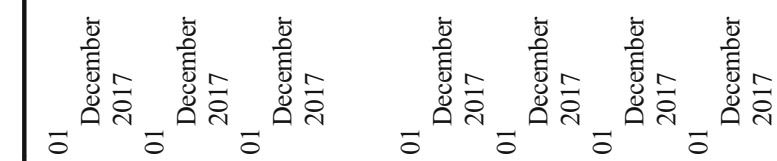

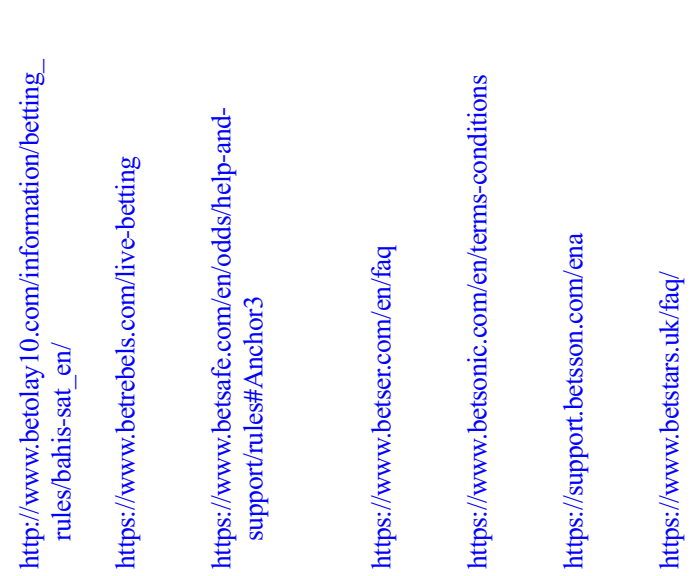

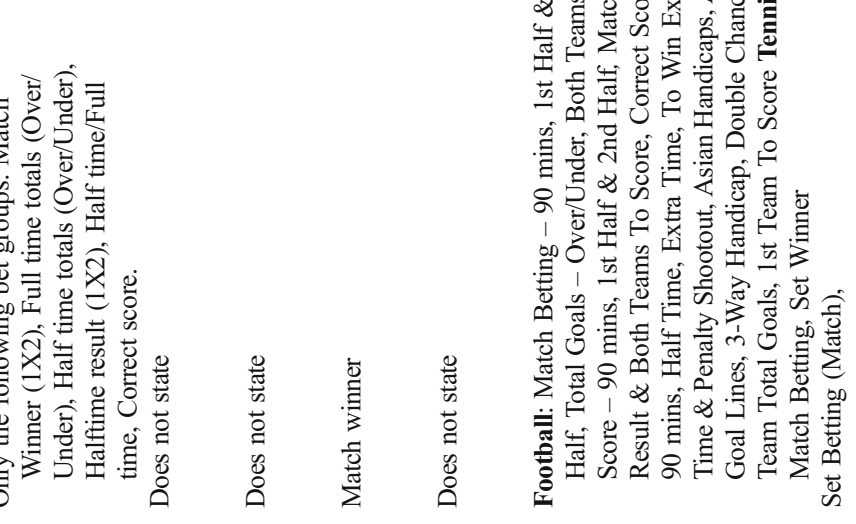

붕

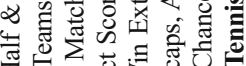

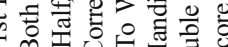

แ艹

ॠण

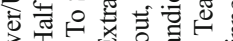

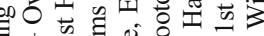

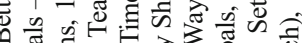

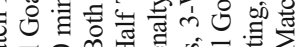

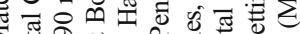

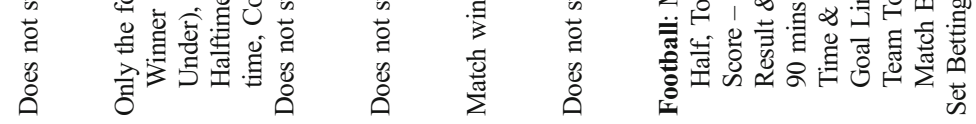

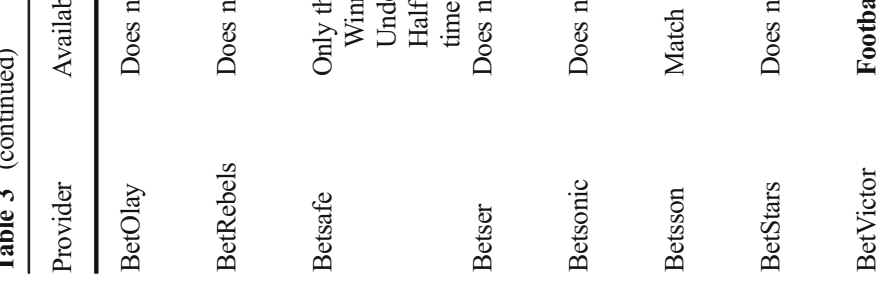




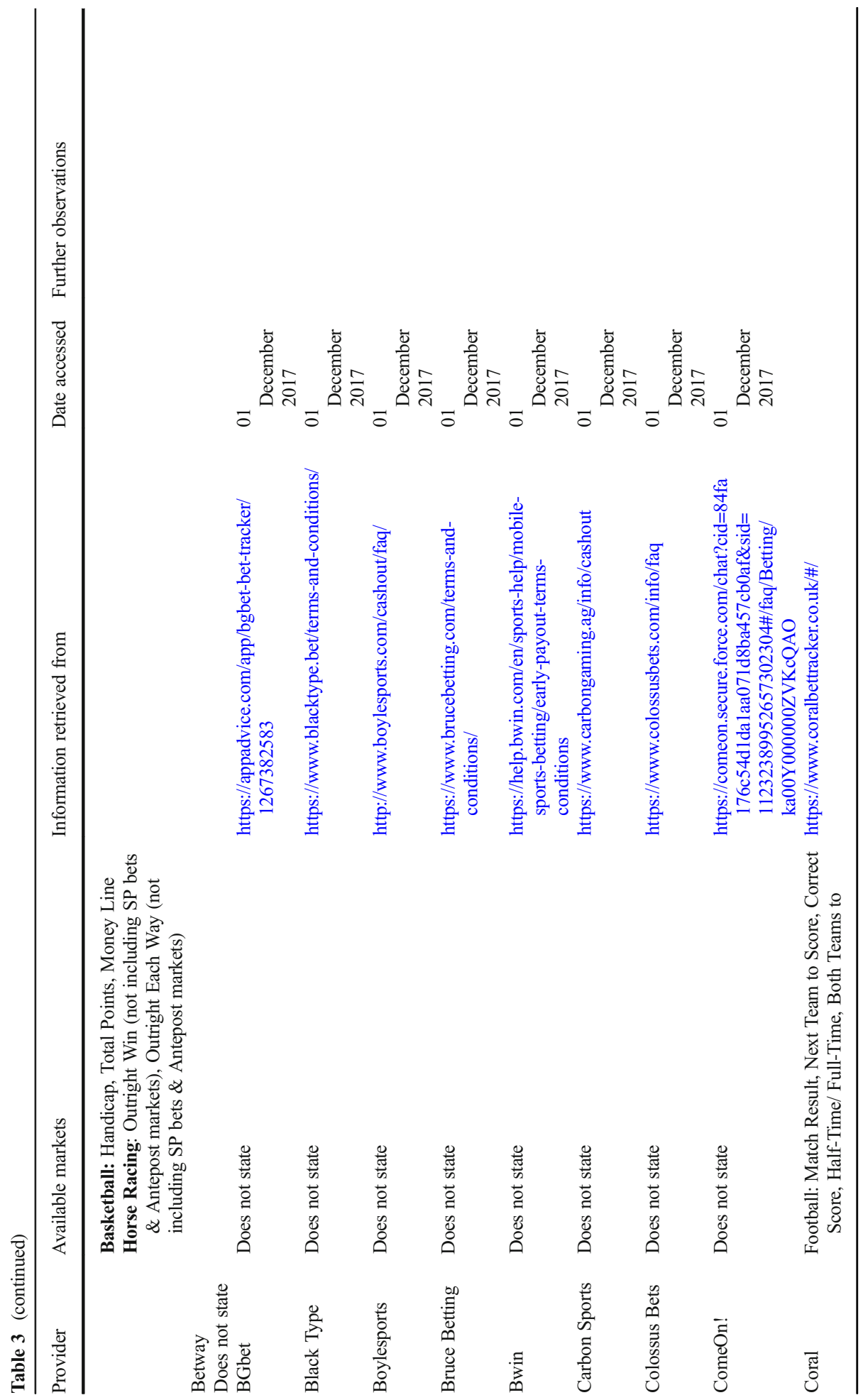




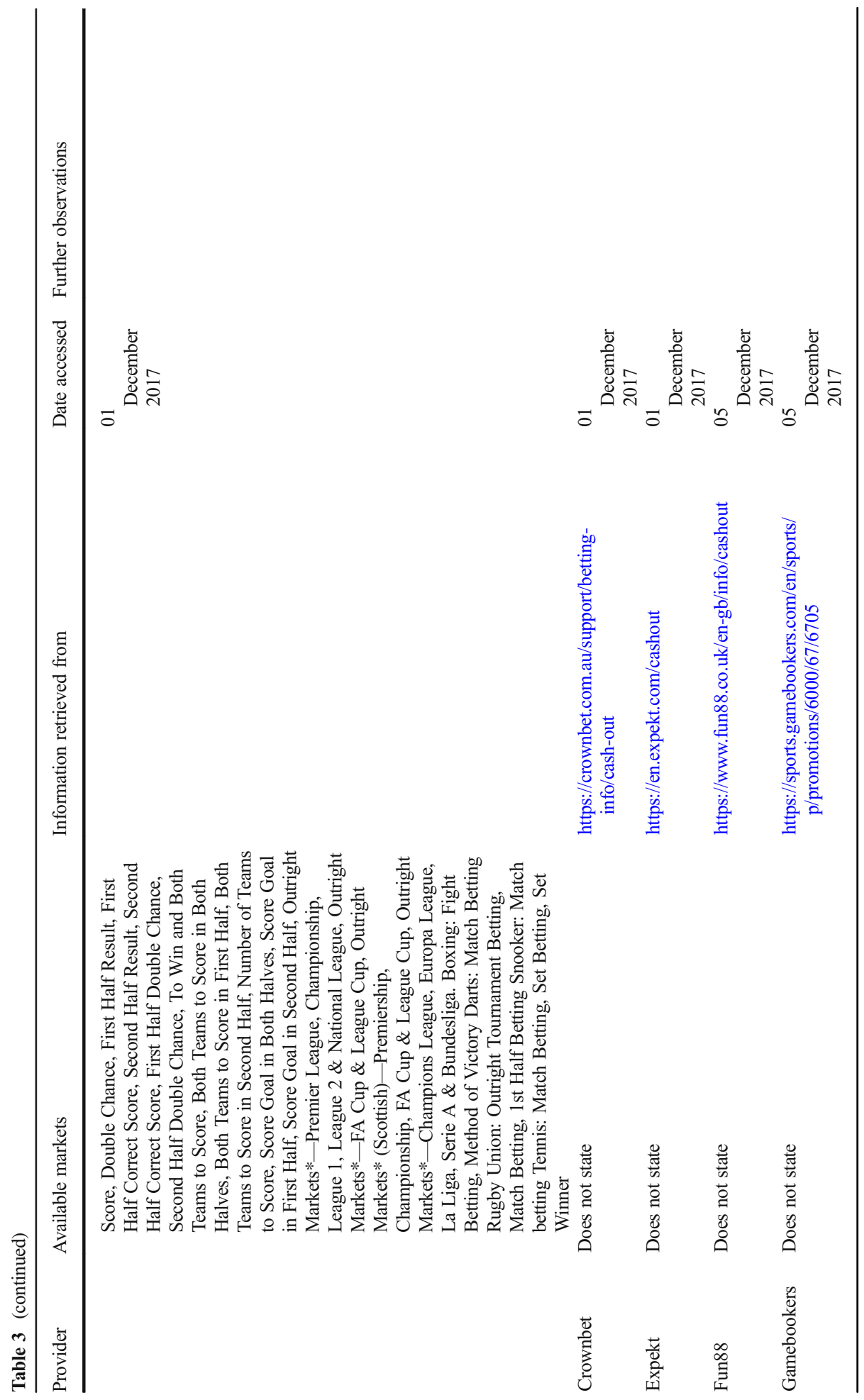




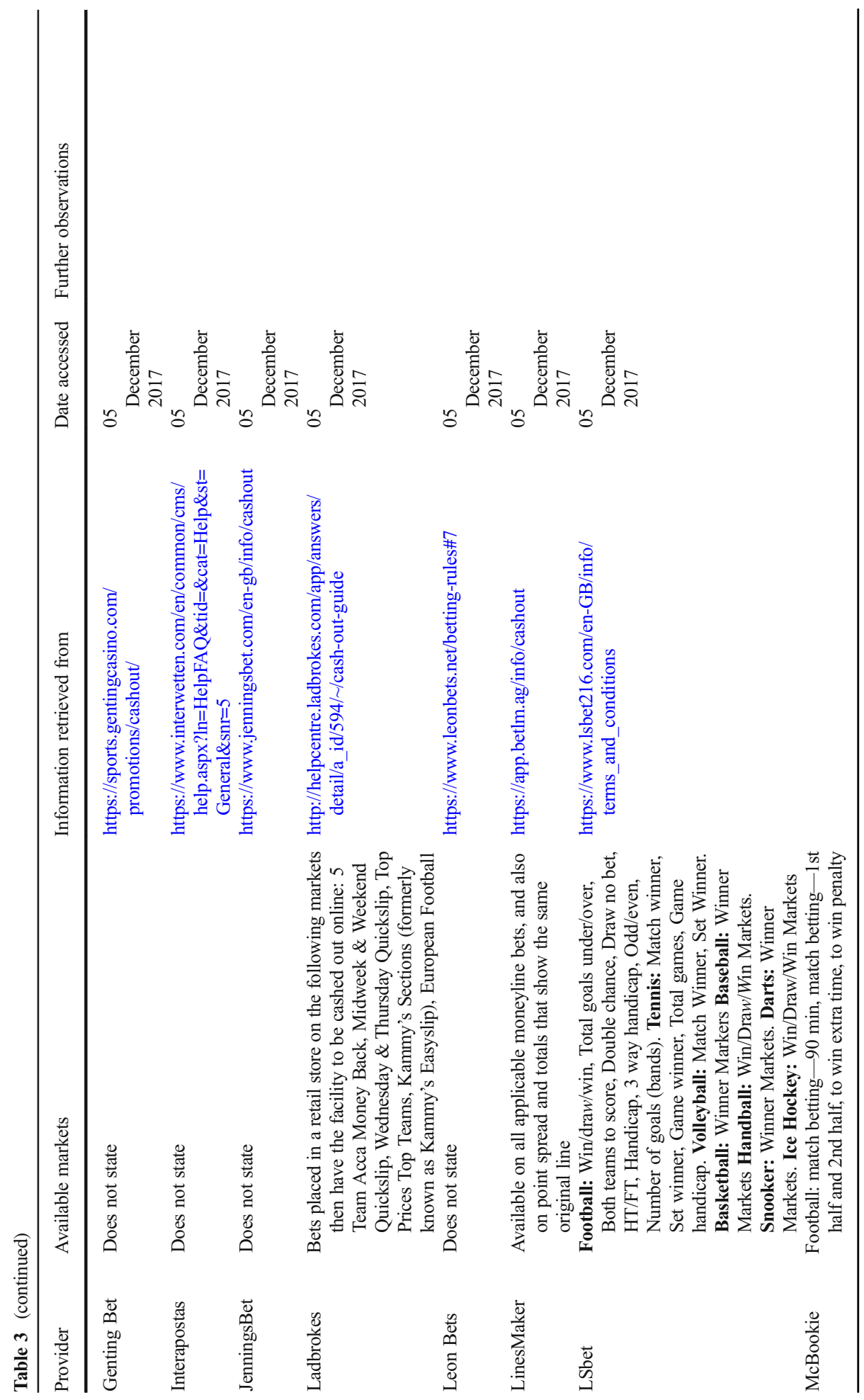




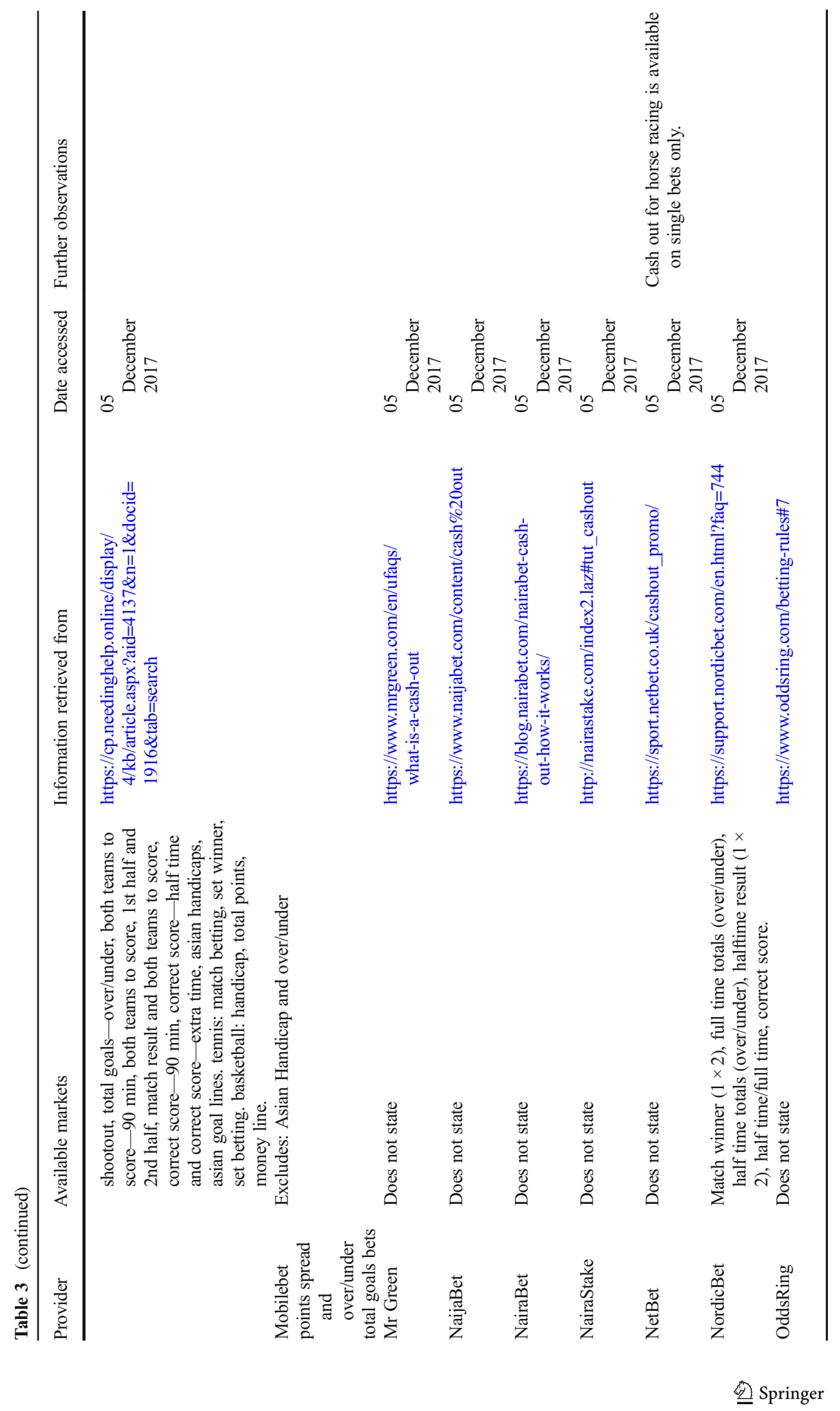




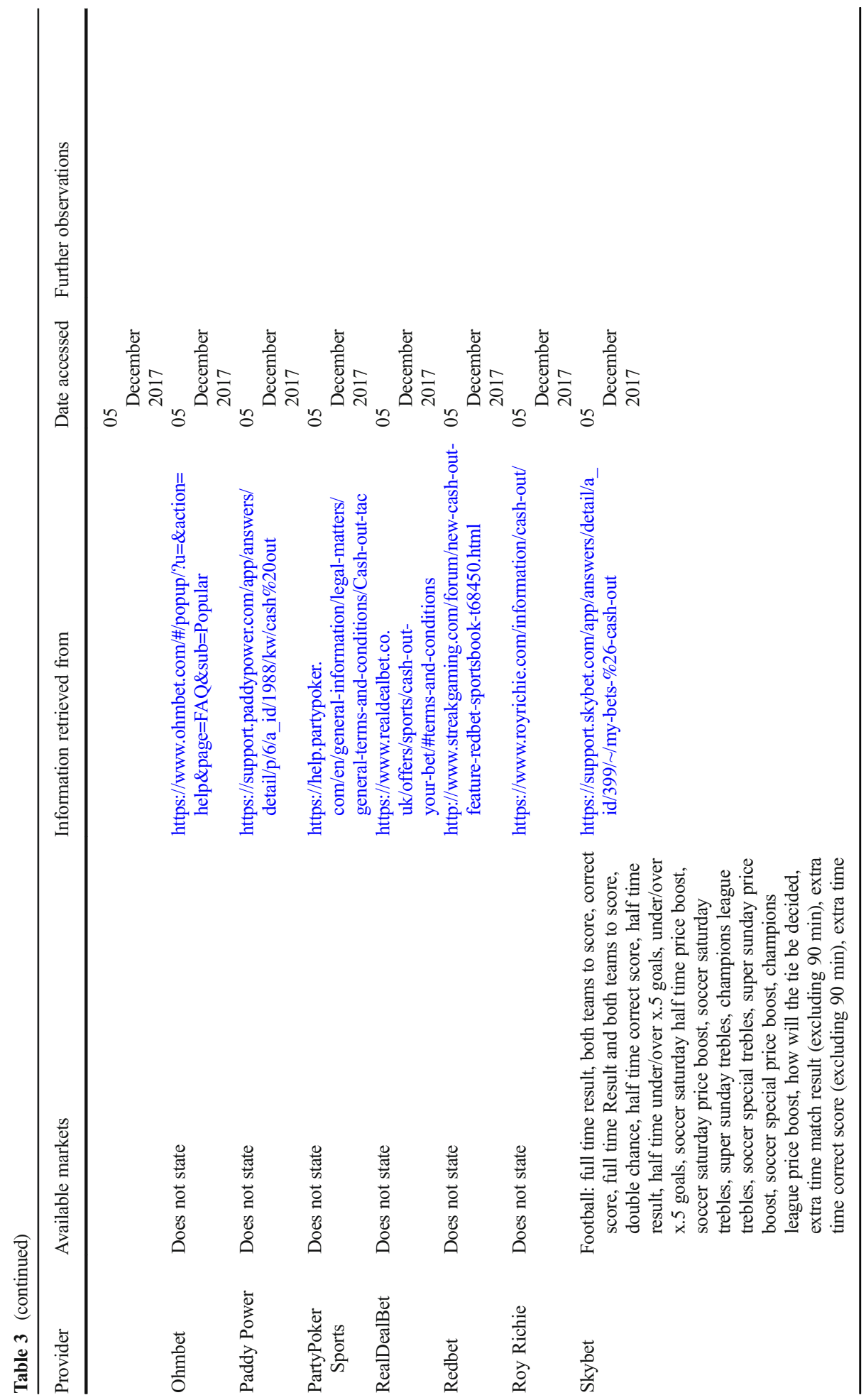




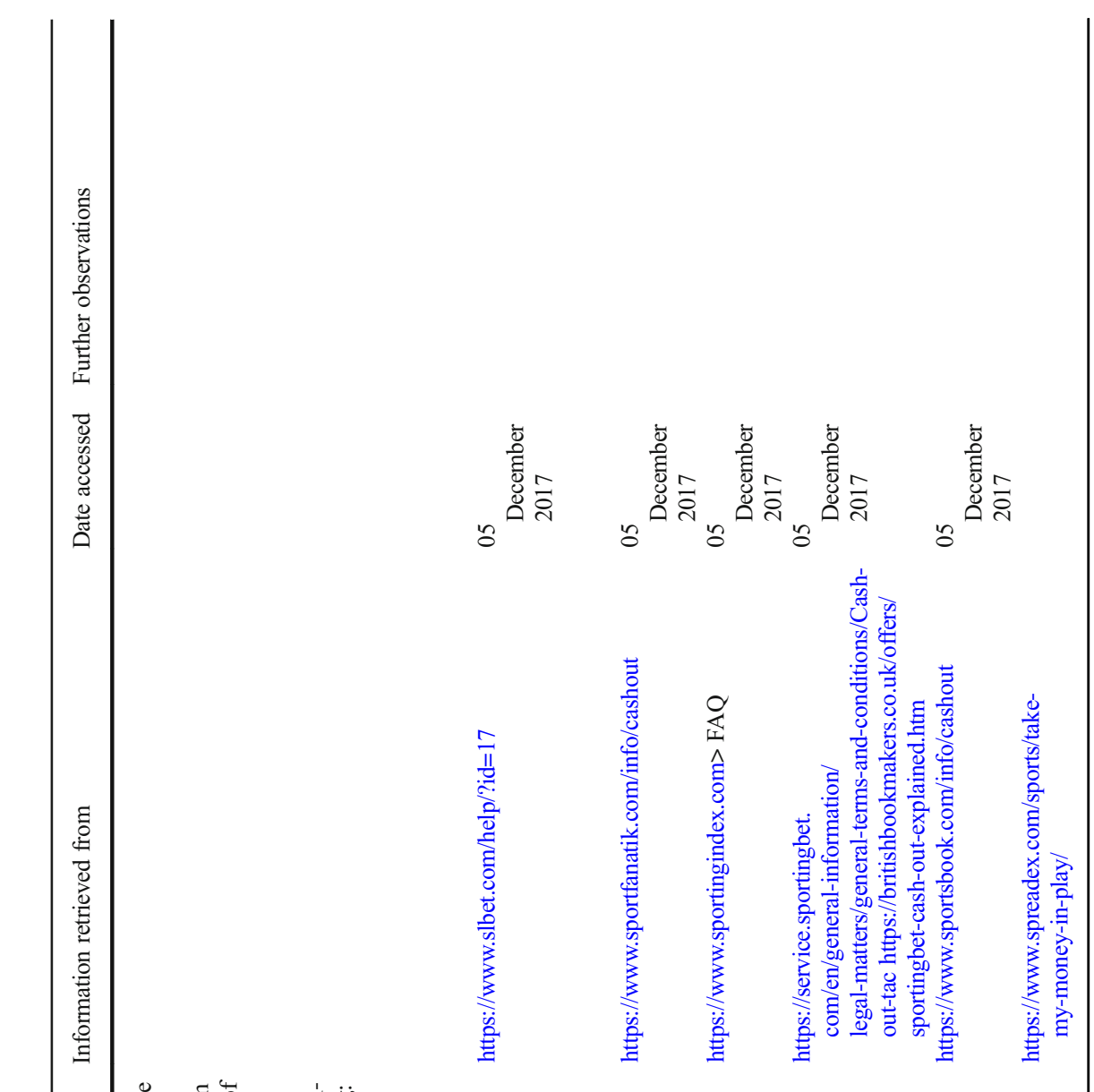

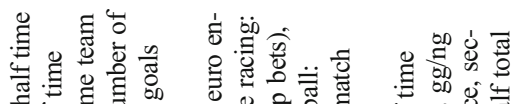

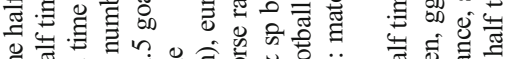

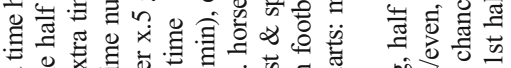

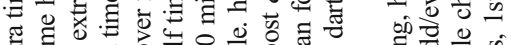

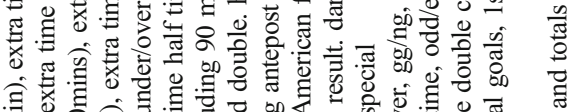

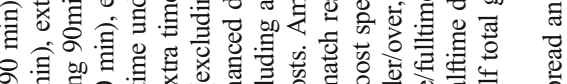

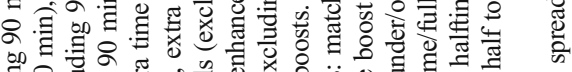

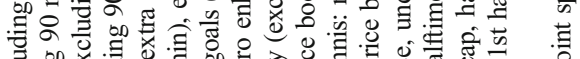

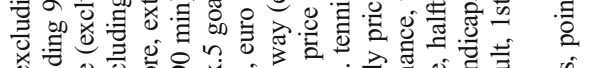




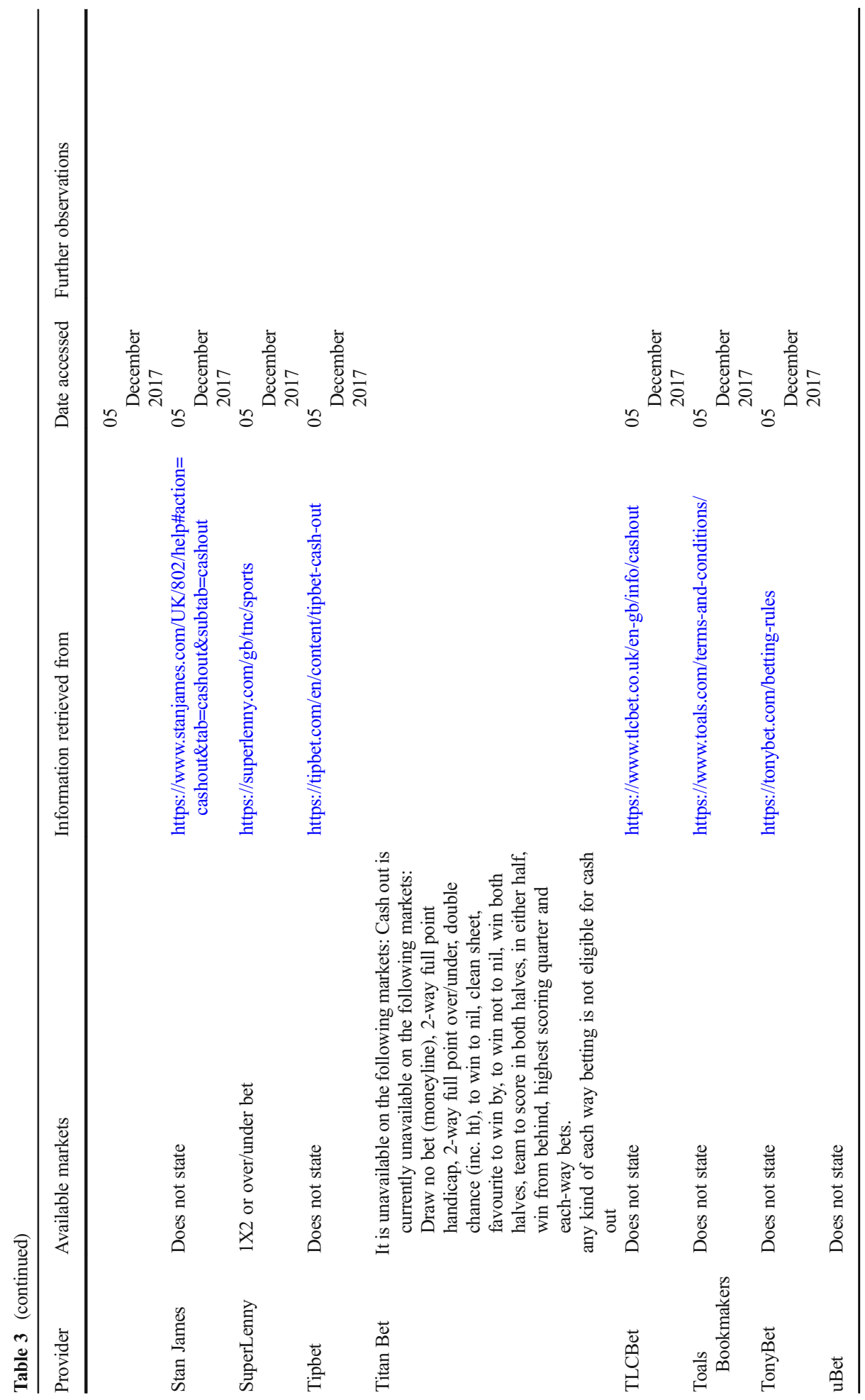




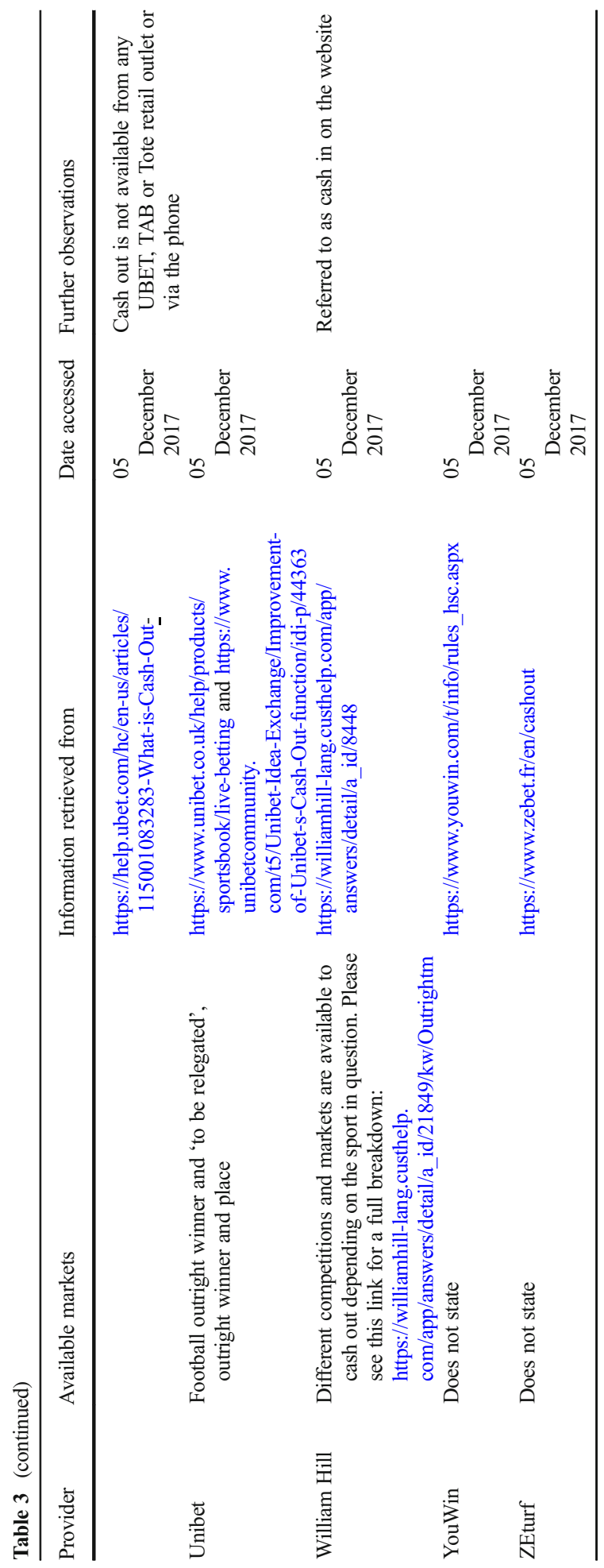


Database search

Scopus $(n=437)$

Web of Science $(n=336)$

PsychARTICLES $(\mathrm{n}=782)$

PsychINFO $(n=284)$

PubMed $(\mathrm{n}=208)$

Total $(n=2,047)$

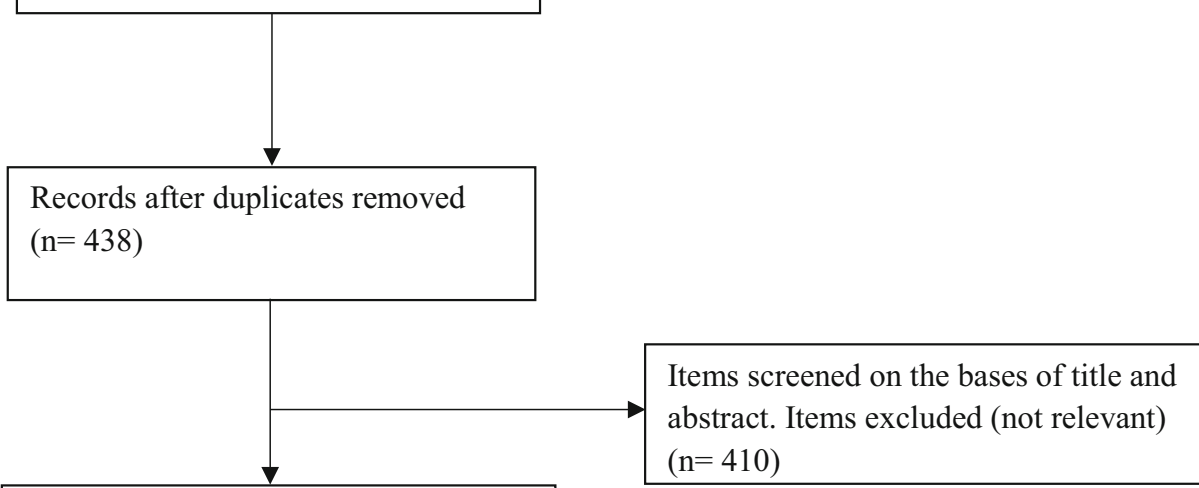

Full texts assessed for eligibility $(\mathrm{n}=$ 28

Full text articles excluded $=19$

\begin{tabular}{|c|c|}
\hline Relevant papers to be included & Google Scholar $(n=5)$ \\
\hline$(n=16)$ & Hand-searching reference lists $(n=2)$ \\
\hline
\end{tabular}

Fig. 1 The flow diagram of the database literature search

Open Access This article is distributed under the terms of the Creative Commons Attribution 4.0 International License (http://creativecommons.org/licenses/by/4.0/), which permits unrestricted use, distribution, and reproduction in any medium, provided you give appropriate credit to the original author(s) and the source, provide a link to the Creative Commons license, and indicate if changes were made.

\section{References}

Bet365 (2017a). Cash out. Retrieved November 21, 2017, from: https:/extra.bet365.com/features/cash-out Bet365 (2017b). Edit bet. Retrieved November 21, 2017, from: https://extra.bet365.com/features/en/edit-bet 
Betfair (2017) What is cash out and how does it work? Retrieved November 21, 2017, from: https:/en-betfair. custhelp.com/app/answers/detail/a id/25/ /exchange\%3A-what-is-cash-out-and-how-does-it-work\%3F

Braverman, J., \& Shaffer, H. J. (2010). How do gamblers start gambling: Identifying behavioural markers for high-risk internet gambling. European Journal of Public Health, 22(2), 273-278. https://doi.org/10.1093 /eurpub/ckp232.

Braverman, J., LaPlante, D. A., Nelson, S. E., \& Shaffer, H. J. (2013). Using cross-game behavioral markers for early identification of high-risk internet gamblers. Psychology of Addictive Behaviors, 27(3), 868-877. https://doi.org/10.1037/a0032818.

Broda, A., LaPlante, D. A., Nelson, S. E., LaBrie, A. R., Bosworth, L. B., \& Shaffer, H. J. (2008). Virtual harm reduction efforts for internet gambling: Effects of deposit limits on actual internet sports gambling behavior. Harm Reduction Journal, 5(12), 27. https://doi.org/10.1186/1477-7517-5-27.

Brosowski, T., Meyer, G., \& Hayer, T. (2012). Analyses of multiple types of online gambling with one provider: An extended evaluation framework of actual online gambling behaviour. International Gambling Studies, 12(3), 405-419. https://doi.org/10.1080/14459795.2012.698295 .

Davis, K., Drey, N., \& Gould, D. (2009). What are scoping studies? A review of the nursing literature. International Journal of Nursing Studies, 46, 1386-1400. https://doi.org/10.1016/j.ijnurstu.2009.02.010.

European Gaming and Betting Association (2016). Market reality. Retrieved November 21, 2017, from: http://www.egba.eu/facts-and-figures/market-reality/

Ferris, J., \& Wynne, H. (2001). The Canadian problem gambling index: Final report. Ottawa: Canadian Centre on Substance Abuse.

Gambling Act (2005). Retrieved December 1, 2017, from: http://www.legislation.gov.uk/ukpga/2005/19 /pdfs/ukpga_20050019_en.pdf

Gambling Commission (2016). In-play (in-running) betting: Position paper. Retrieved November 21, 2017, from: http:/www.gamblingcommission.gov.uk/pdf/In-running-betting-position-paper.pdf

Gambling Commission (2017). Gambling participation in 2016: Behaviour, awareness and attitudes. Annual report. Retrieved February 5, 2018, from: http://www.gamblingcommission.gov.uk/PDF/surveydata/Gambling-participation-in-2016-behaviour-awareness-and-attitudes.pdf

Gaming Intelligence (2014). William Hill launches cashout feature for mobile. January 21. Retrieved November 21, 2017, from: http:/www.gamingintelligence.com/marketing/23957-william-hill-launches-cashoutfeature-for-mobile-devices

Gebauer, L., LaBrie, R., \& Shaffer, H. J. (2010). Optimizing DSM-IV-TR classification accuracy: A brief biosocial screen for detecting current gambling disorders among gamblers in the general household population. Canadian Journal of Psychiatry, 55(2), 82-09. https://doi.org/10.1177/070674371005500204 .

Gray, H. M., LaPlante, D. A., \& Shaffer, H. J. (2012). Behavioral characteristics of internet gamblers who trigger corporate responsible gambling interventions. Psychology of Addictive Behaviors, 26(3), 527-535. https://doi.org/10.1037/a0028545.

Griffiths, M. D. (1994). The role of cognitive bias and skill in fruit machine gambling. British Journal of Psychology, 85, 351-369. https://doi.org/10.1111/j.2044-8295.1994.tb02529.x.

Griffiths, M. D. (2012). Mind games (A brief psychosocial overview of in-play betting). $i$-Gaming Business Affiliate, June/July, 44.

Griffiths, M. D. (2014). The use of behavioural tracking methodologies in the study of online gambling. SAGE Research Methods Cases. London: Sage. https://doi.org/10.4135/978144627305013517480.

Griffiths, M. D., \& Auer, M. (2013). The irrelevancy of game-type in the acquisition, development, and maintenance of problem gambling, 3, 621. doi: https://doi.org/10.3389/fpsyg.2012.00621.

Griffiths, M. D., \& Auer, M. (2016). Should voluntary self-exclusion by gamblers be used as a proxy measure for problem gambling? Journal of Addiction Medicine and Therapy, 2(2), 00019. https://doi.org/10.15406 /mojamt.2016.02.00019.

Griffiths, M. D., Parke, A., Wood, R., \& Parke, J. (2006). Internet gambling: An overview of psychosocial impacts. UNLV Gaming Research \& Review Journal, 10, 27-39.

Harris, A., \& Griffiths, M. D. (2017). The impact of speed of play in gambling on psychological and behavioural factors: A critical review. Journal of Gambling Studies. https://doi.org/10.1007/s10899-017-9701-7 .

Hing, N., Cherney, L., Gainsbury, S., Lubman, D., Wood, R., \& Blaszczynski, A. (2014a). Maintaining and losing control during internet gambling: A qualitative study of gamblers' experiences. New Media and Society, 17(7), 1075-1095. https://doi.org/10.1177/1461444814521140 .

Hing, N., Gainsbury, S., Blaszczynski, A., Wood, R., Lubman, D., \& Russell, A. (2014b). Interactive gambling. Melbourne: Gambling Research Australia.

Hing, N., Vitartas, P., \& Lamont, M. (2014c). Promotion of gambling and live betting odds during televised sport: influences on gambling participation and problem gambling. Brisbane: Queensland Department of Justice. doi: https://doi.org/10.13140/2.1.1643.8087. 
Hing, N., Lamont, M., Vitartas, P., \& Fink, E. (2015). Sports-embedded gambling promotions: a study of exposure, sports betting intention and problem gambling amongst adults. International Journal of Mental Health and Addiction, 68, 2057-2066. https://doi.org/10.1007/s11469-014-9519-9.

Hing, N., Russell, A. M. T., Vitartas, P., \& Lamont, M. (2016). Demographic, behavioural and normative risk factors for gambling problems amongst sports bettors. Journal of Gambling Studies, 32(2), 625-641. https://doi.org/10.1007/s10899-015-9571-9.

Hing, N., Li, E., Vitartas, P., \& Russell, A. M. T. (2017a). On the spur of the moment: Intrinsic predictors of impulse sports betting. Journal of Gambling Studies. https://doi.org/10.1007/s10899-017-9719-x .

Hing, N., Russell, A.M.T., Lamont, M \& Vitartas (2017b). Bet anywhere, anytime: An analysis of internet sports bettors' responses to gambling promotions during sports broadcasts by problem gambling severity. Journal of Gambling Studies, 33(4), 1051-1065. doi: https://doi.org/10.1007/s10899-017-9671-9 .

Interactive Gambling Act (2001). Retrieved December 2, from: https://www.legislation.gov.au/Details/C2017 C00291

Jackson, L. (2015). Live betting explosion at Bet365. Online-Betting.me.uk, July 6. Retrieved November 21, 2017, from: https:/www.online-betting.me.uk/news/bet365-reveal-80-of-sports-betting-revenue-comesfrom-live-in-play-betting.html

James, R. J. E., O'Malley, C., \& Tunney, R. J. (2016). Understanding the psychology of mobile gaming: A behavioural synthesis. British Journal of Psychology, 108(3), 608-625. https://doi.org/10.1111/bjop.12226.

Kavanagh, J., Trouton, A., Oakley, A., \& Harden, A. (2005). A scoping review of the evidence for incentive schemes to encourage positive health and other social behaviors in young people. London: EPPI-Centre, Social Science Research Unit, Institute of Education.

LaBrie, R. A., Laplante, D. A., Nelson, S. E., Schumann, Æ. A., \& Shaffer, H. J. (2007). Assessing the playing field: A prospective longitudinal study of internet sports gambling behavior. Journal of Gambling Studies, 23(3), 347-362. https://doi.org/10.1007/s10899-007-9067-3 .

Ladbrokes (2017) Edit my acca (Article No. 462). Retrieved November 21, 2017, from: http://helpcentre. ladbrokes.com/app/answers/detail/a_id/462/ /edit-my-acca

Lamont, M., Hing, N., \& Virtartas, P. (2016). Affective responses to gambling promotions during televised sport: A qualitative analysis. Sport Management Review, 19(3), 319-331. https://doi.org/10.1016/j. smr.2015.06.002 .

Langer, E. J. (1975). The illusion of control. Journal of Personality and Social Psychology, 31(2), 311-328. https://doi.org/10.1037/0022-3514.32.2.311.

LaPlante, D. A., Schumann, A., LaBrie, R. A., \& Shaffer, H. J. (2008). Population trends in internet sports gambling. Computers in Human Behavior, 24, 2399-2414. https://doi.org/10.1016/j.chb.2008.02.015.

LaPlante, D. A., Nelson, S. E., \& Gray, H. M. (2014). Breadth and depth involvement: Understanding internet gambling involvement and its relationship to gambling problems. Psychology of Addictive Behaviors, 28(2), 396-403. https://doi.org/10.1037/a0033810 .

Lopez-Gonzalez, H., \& Griffiths, M. D. (2016a). Understanding the convergence of markets in online sports betting. International Review for the Sociology of Sport, 1-17. https://doi.org/10.1177 /1012690216680602.

Lopez-Gonzalez, H., \& Griffiths, M. D. (2016b). Is European online gambling regulation adequately addressing in-play betting advertising? Gaming Law Review and Economics, 20, 495-503. https://doi.org/10.1089 /glre.2016.2064.

Lopez-Gonzalez, H., \& Griffiths, M. D. (2017). "Cashing out" in sports betting: implications for problem gambling and regulation. Gaming Law Review, 21(4), 323-326. https://oi.org/10.1089/glr2.2017.2144.

Lopez-Gonzalez, H., Guerrero-Solé, F., Estévez, A., \& Griffiths, M. D. (2017a). Betting is loving and bettors are predators: A conceptual metaphor approach to online sports betting advertising. Journal of Gambling Studies. https://doi.org/10.1007/s10899-017-9727-x .

Lopez-Gonzalez, H., Guerrero-Solé, F., \& Griffiths, M. D. (2017b). A content analysis of how 'normal' sports betting behaviour is represented in gambling advertising. Addiction Research \& Theory. https://doi. org/10.1080/16066359.2017.1353082.

Lopez-Gonzalez, H., Estévez, A., \& Griffiths, M. D. (2017c). Marketing and advertising online sports betting: A problem gambling perspective. Journal of Sport and Social Issues, 41(3), 256-272. https://doi.org/10.1177 /0193723517705545.

Lopez-Gonzalez, H., Estévez, A., \& Griffiths, M. D. (2017d). Controlling the illusion of control: A grounded theory of sports betting advertising in the UK. International Gambling Studies, 18, 39-55. https://oi. org/10.1080/14459795.2017.1377747.

Lopez-Gonzalez, H., Estévez, A., \& Griffiths, M. D. (2018). Internet-based structural characteristics of sports betting and problem gambling severity: Is there a relationship? International Journal of Mental Health Addiction. https://doi.org/10.1007/s11469-018-9876-x . 
Mays, N., Roberts, E., \& Popay, J. (2001). Synthesising research evidence. In N. Fulop, P. Allen, A. Clarke, \& N. Black (Eds.), Studying the organisation and delivery of health services: Research methods (pp. 188-215). London: Routledge.

McCormack, A., \& Griffiths, M. D. (2013). A scoping study of the structural and situational characteristics of internet gambling. International Journal of Cyber Behavior, Psychology and Learning, 3(1), 29-49. https://doi.org/10.4018/ijcbpl.2013010104.

Nelson, S. E., Laplante, D. A., Peller, A. J., Schumann, A., Labrie, R. A., \& Shaffer, H. J. (2008). Real limits in the virtual world: Self-limiting behavior of internet gamblers. Journal of Gambling Studies, 24(4), 463-477. https://doi.org/10.1007/s10899-008-9106-8 .

Odds Checker (2017). In-play. Retrieved November 21, 2017 from: https://www.oddschecker.com/bettingterms/in-play

Parke, J., \& Griffiths, M. D. (2007). The role of structural characteristics in gambling. In G. Smith, D. Hodgins, \& R. Williams (Eds.), Research and measurement issues in gambling studies (pp. 211-243). New York: Elsevier.

SBTech (2017). SBTech launches mobile-focused "Add2Bet" enhancement to its industry-leading Sportsbook. Retrieved November 21, 2017, from: https://www.sbtech.com/sbtech-launches-mobile-focused-add2betenhancement/

Shaffer, H. J., Allyson, J. P., LaPlante, D. A., Nelson, S. E., \& Labrie, R. A. (2010). Toward a paradigm shift in Internet gambling research: From opinion and self-report to actual behavior. Addiction Research \& Theory, 18, 270-283. https://doi.org/10.3109/16066350902777974 .

Slutske, W. S. (2006). Natural recovery and treatment-seeking in pathological gambling: Results of two U.S. national surveys. American Journal of Psychiatry, 163(2), 297-302. https://oi.org/10.1176/appi. ajp.163.2.297.

Streeter, J. (2017) Peter Woodfine - total performance data - in-play betting is 'vital for racing's future'. SBC News, November 1. Retrieved November 21, 2017, from: https://sbcnews.co.uk/features/2017/11/01/peterwoodfine-total-performance-data-play-horse-racing-betting-absolutely-vital-racings-future)/.

The Allen Consulting Group (2012) Research for the review of the Interactive Gambling Act 2001: Online gambling and 'in-the-run' betting”. Retrieved February 5, 2018, from: http:/www.acilallen.com.au/cms files/ACIL OnlineGambling2012.pdf

Top 100 Bookmakers (2017). Comparative directory of online bookmakers. Retrieved November 21, 2017, From: http://www.top100bookmakers.com/completelist.php

Wardle, H., Moody, A., Griffiths, M. D., Orford, J., \& Volberg, R. (2011). Defining the online gambler and patterns of behaviour integration: Evidence from the British gambling prevalence survey 2010. International Gambling Studies, 11, 339-356. https://doi.org/10.1080/14459795.2011.628684 .

Wood, G. (2017). Bookmakers to embrace 'big data' to shift racing's betting future. The Guardian, October 6. https:/www.theguardian.com/sport/2017/oct/06/bookmaker-launch-mobile-app-betting-live-horse-races

Xuan, Z., \& Shaffer, H. (2009). How do gamblers end gambling: Longitudinal analysis of internet gambling behaviors prior to account closure due to gambling related problems. Journal of Gambling Studies, 25, 239252. https://doi.org/10.1007/s10899-009-9118-z . 